\title{
Review Article \\ Peripheral Blood Mononuclear Cells as a Laboratory to Study Dementia in the Elderly
}

\author{
Beatrice Arosio, ${ }^{1,2}$ Claudio D'Addario, ${ }^{3,4}$ Cristina Gussago, ${ }^{2}$ Martina Casati, ${ }^{1}$ Enzo Tedone, ${ }^{2}$ \\ Evelyn Ferri, ${ }^{2}$ Paola Nicolini, ${ }^{1}$ Paolo D. Rossi, ${ }^{1}$ Mauro Maccarrone, ${ }^{5,6}$ and Daniela Mari ${ }^{1,2}$ \\ ${ }^{1}$ Geriatric Unit, Fondazione Ca' Granda, IRCCS Ospedale Maggiore Policlinico, Via Pace 9, 20122 Milan, Italy \\ ${ }^{2}$ Geriatric Unit, Department of Medical Sciences and Community Health, University of Milan, Via Pace 9, 20122 Milan, Italy \\ ${ }^{3}$ Faculty of Bioscience and Technology for Food, Agriculture and Environment University of Teramo, Piazza Aldo Moro 45, \\ 64100 Teramo, Italy \\ ${ }^{4}$ Department of Clinical Neuroscience, Karolinska Institutet CMM L8:01, 17176 Stockholm, Sweden \\ ${ }^{5}$ European Center for Brain Research, Santa Lucia Foundation, IRCCS, Via del Fosso di Fiorano 64, 00143 Rome, Italy \\ ${ }^{6}$ Center of Integrated Research, Campus Bio-Medico University of Rome, Via Alvaro del Portillo 21, 00128 Rome, Italy \\ Correspondence should be addressed to Beatrice Arosio; beatrice.arosio@unimi.it
}

Received 31 January 2014; Accepted 28 March 2014; Published 30 April 2014

Academic Editor: Maria de Luca

Copyright (C) 2014 Beatrice Arosio et al. This is an open access article distributed under the Creative Commons Attribution License, which permits unrestricted use, distribution, and reproduction in any medium, provided the original work is properly cited.

\begin{abstract}
The steady and dramatic increase in the incidence of Alzheimer's disease (AD) and the lack of effective treatments have stimulated the search for strategies to prevent or delay its onset and/or progression. Since the diagnosis of dementia requires a number of established features that are present when the disease is fully developed, but not always in the early stages, the need for a biological marker has proven to be urgent, in terms of both diagnosis and monitoring of AD. AD has been shown to affect peripheral blood mononuclear cells (PBMCs) that are a critical component of the immune system which provide defence against infection. Although studies are continuously supplying additional data that emphasize the central role of inflammation in AD, PBMCs have not been sufficiently investigated in this context. Delineating biochemical alterations in AD blood constituents may prove valuable in identifying accessible footprints that reflect degenerative processes within the Central Nervous System (CNS). In this review, we address the role of biomarkers in AD with a focus on the notion that PBMCs may serve as a peripheral laboratory to find molecular signatures that could aid in differential diagnosis with other forms of dementia and in monitoring of disease progression.
\end{abstract}

\section{Introduction}

The prevalence of dementia has increased globally, most noticeably in the ageing populations of the developed world. Alzheimer's disease (AD) is the most common type of dementia (60\% of cases). Individuals affected by $\mathrm{AD}$ are 5.4 million in the United States and more than 33.9 million worldwide [1]. Moreover, $\mathrm{AD}$ prevalence is estimated to triple over the next 40 years and this will place a heavy burden on society and its health-care systems in terms of both economic costs and human impacts. The steady and dramatic increase in the incidence of $\mathrm{AD}$ and the lack of effective treatments have stimulated the search for strategies to prevent or delay its onset and/or progression.
There is general agreement that the epidemiological impact of dementia can be reduced by detecting and treating classical vascular risk factors since different studies provide evidence in favour of a coexistence of vascular and degenerative components in its pathogenesis [2].

In western countries vascular dementia (VD) is the second most common cause of dementia after AD among the elderly. A meta-analysis of the European studies on the incidence of dementia showed that VD constitutes $17.6 \%$ of all dementias [3]. In Europe and North America, AD is more common than VD in a 2:1 ratio; in contrast, in Japan and China VD accounts for almost $50 \%$ of all dementias. Also, the possibility of concomitant $\mathrm{AD}$ often confounds the relationship between cerebrovascular disease and VD. 
AD is characterized by neurofibrillary tangles (NFT) and extracellular amyloid deposits. The former are composed of intraneuronal aggregates of hyperphosphorylated tau proteins and the latter are made of amyloid-beta $(\mathrm{A} \beta)$ peptides stemming from the sequential cleavage of a transmembrane precursor named amyloid precursor protein (APP).

Vascular pathology, namely arteriosclerosis, endothelial proliferation, and neovascularization, have been often found to be associated with NTF and amyloid plaques [4].

A number of autopsy studies have confirmed that among cases of dementia, AD-related pathology was associated with vascular lesions in nearly one-third of cases [5]. In addition, many epidemiological reports have demonstrated that the presence of vascular factors increases the risk of developing AD.

However, it is still a matter of controversy whether neurodegenerative $\mathrm{AD}$-like disease and cerebrovascular lesions are coexisting but unrelated pathologies or whether they represent different results of synergistic pathogenic mechanisms.

It is hypothesized that an alteration of the neurovascular unit, which is the functional unit encompassing vascular cells, astrocytes, and perivascular neurons, is an early event in the pathogenesis of $\mathrm{AD}$ [6]. Dysfunction of the neurovascular unit results in impaired blood brain barrier (BBB) functions, dysregulation of cerebral blood flow, and impairment of $\mathrm{A} \beta$ clearance leading to an increase of oligomers and soluble A $\beta$ forms [7]. Vascular oxidative stress and inflammation underlie many of these deleterious effects and are potential therapeutic targets even if, at present, there is no cure for AD and only a few medications aimed at slowing down memory deficits and clinical symptoms are available, with limited benefits.

Consequently, there is a pressing need for the identification of biomarkers that will aid in the differential diagnosis between $\mathrm{AD}$ and other forms of dementia and that will allow the detection of $\mathrm{AD}$ at early stages. Within the scenario of dementia, biomarker research may thus play an important role in paving the way towards novel diagnostic or therapeutic strategies.

\section{Biomarkers}

A biomarker is a characteristic that can be objectively measured and evaluated as an indicator of normal biological processes, pathogenic processes, or pharmacological responses to a therapeutic intervention $[8,9]$. Many tests commonly used in clinical practice are biomarkers; biochemical tests provide soluble biomarkers, whereas physiological assessment and imaging measures provide anatomical and functional biomarkers. The majority have been identified on the basis of biological insight or underlying physiology. With increasing knowledge and practical experience, many of these tests have evolved into measurable end points in clinical research, applied as indicators of change, be it for the better or for the worse [10].

Biomarkers have also gained an important role in the field of clinical management and have established a close link with bedside medicine, by providing metrics of quality in medical care alongside meaningful costing. With effective translation into many clinical guidelines, biomarkers can facilitate the delivery of evidence-based medical care [11].

The evaluation of biomarkers may aid in the identification of diseases and may also allow correlations to be made with the progression or the susceptibility to a disease or a given treatment.

Yet, single biomarkers are unlikely to capture the complex process of human pathophysiology. Thus research may need to be geared towards sets of biomarkers, reflecting different, but intercalated, processes, which may enable a better assessment of disease states.

Biomarkers can be measured, for instance, in saliva, sweat, breath, blood/serum, urine, and cerebrospinal fluid (CSF). The fact that the collection of these biological fluids is significantly less invasive than biopsies is an important practical issue when studying neurodegenerative disorders like $\mathrm{AD}[12]$.

It has been reported that the sensitivity (definitely positive/(definitely positive + false negative)) of an "ideal" biomarker to detect AD should be at least $85 \%$. Similarly, the specificity (definitely negative/(definitely negative + false positive)) in differentiating $\mathrm{AD}$ patients from controls and from patients with other forms of dementia should be at least $75 \%[10]$.

2.1. Biomarkers and Alzheimer. Despite the enormous advances in modern medicine, the diagnosis of $\mathrm{AD}$ remains largely clinical, based on patient history/examination, neuropsychological testing, and imaging techniques. Unfortunately the clinical diagnosis of AD suffers from limitations in that it only allows us to speak of probable or possible AD [13] with a $93 \%$ sensitivity and a 55\% specificity. Furthermore, the diagnosis becomes far more difficult in the case of early or unusual presentations of the disease.

With the expansion of current knowledge on $\mathrm{AD}$ and the increasing availability of technical tools, there is an emerging need for the development of accurate biochemical and imaging tests that support the diagnosis [14, 15]. In this context the diagnostic criteria for AD proposed in 2007 [14] highlight the usefulness of genetic studies since they would enable a definite diagnosis to be made based on the demonstration of mutations in any of the three genes responsible for autosomal dominant disease: the gene for APP on chromosome 21, for presenilin 1 (on chromosome 14), and for presenilin 2 (on chromosome 1).

As to the more prevalent sporadic cases of $\mathrm{AD}$, the need for a biological marker has proven to be urgent, for both the diagnosis and monitoring of the disease $[16,17]$.

Indeed, an ideal biomarker for $\mathrm{AD}$ would assist in the identification of preclinical disease, early disease diagnosis, staging of disease progression, and response to treatment [18]. Early diagnosis and identification of preclinical AD are particularly important issues considering the development of underlying neuropathology in those yet to display clinical symptoms. In particular, Mild Cognitive Impairment (MCI) is a well-described prodromal state of cognitive decline preceding dementia, with an accelerated conversion to $\mathrm{AD}$ estimated at $10-12 \%$ per year [19]. 
Over the past decade, biomarker discovery has become a rapidly advancing area of $\mathrm{AD}$ research.

With the development of structural, functional, and molecular techniques, neuroimaging is increasingly being employed as a diagnostic and prognostic tool in AD. Quantitative magnetic resonance imaging (MRI) is used to assess neurodegenerative changes in $\mathrm{AD}$, which include reducing whole brain volume and cortical thickness associated with ventricular enlargement [20]. Early degeneration is also apparent in the hippocampus, entorhinal cortex, and medial temporal lobe of AD patients relative to controls [21]. In fact, MRI-determined hippocampal atrophy is currently the most established structural biomarker for $\mathrm{AD}$ and has been shown to predict the conversion from MCI to AD in about $80 \%$ of cases [22]. Additional neuroimaging techniques include functional MRI (fMRI), positron emission tomography (PET), and single-photon emission computed tomography (SPECT) which reveal abnormalities in brain synaptic activity, metabolism, and perfusion, respectively. Recent advances include the development of a number of amyloid-binding compounds, the most extensively studied being 11C-PIB (Pittsburgh Compound B, PIB). Several PET studies have detected an increased uptake of PIB in AD patients, which was found to correlate with the extent of cerebral atrophy and memory impairment [23]. Notably, longitudinal studies suggest that PIB imaging is able to predict the progression from normal cognition and MCI to symptomatic $\mathrm{AD}[24]$.

In view of the close relationship of the CSF with the brain and spinal cord, it is believed that the composition of this fluid may reflect biochemical changes in the CNS and thus provide information on the pathological changes occurring in neurodegenerative disorders [18]. Multiple studies have examined CSF for potential AD biomarkers. It is generally recognized that $\mathrm{AD}$ subjects compared to agematched controls exhibit decreased CSF levels of soluble A $\beta 42$ and increased CSF levels of total tau and phosphotau [25]. Importantly, diagnostic accuracy is improved by using the tau/A $\beta 42$ ratio instead of either single biomarker, and this is reflected in an increase in sensitivity and specificity to $86 \%$ and $97 \%$, respectively [26]. Moreover, this combination also appears to predict the subsequent development of AD in both cognitively normal and MCI patients $[27,28]$. These findings have thus established CSF A $\beta 42$ and tau as the most sensitive and specific diagnostic and predictive biomarkers for AD.

It should however be remarked that although neuroimaging and CSF biomarkers seem to be the most promising, they also carry some limitations. They are generally expensive to perform routinely and lumbar puncture is invasive and often unpleasant. Moreover a large variability exists in the literature as to CSF biomarker diagnostic accuracies and cutoffs, hampering or delaying their everyday application in the clinical setting $[29,30]$ and their potential use as indicators of prodromal AD.

Also, it is worth noting that the process of biomarker discovery involves many critical steps including study design, sample preparation, protein and peptide separation and identification, and bioinformatics and data integration issues that must be carefully controlled before achieving independent confirmation and validation.

Lastly, patient age is an important confounding factor in these biomarker studies and could explain some of the variability in published diagnostic accuracies and cut-offs [30]. Indeed a consistent number of subjects affected by Lewy Body Dementia (LBD), Frontotemporal Lobar Degeneration (FTLD), VD, and Corticobasal Degeneration (CBD) display an $\mathrm{AD}$-like CSF biomarker profile [31].

\section{Inflammation and Alzheimer}

In the human brain several cell types are responsible for initiating and amplifying a specific inflammatory response. In $\mathrm{AD}$ signs of an inflammatory activation of microglia and astroglia are present both inside and outside amyloid deposits. Cell cultures and animal models suggest an interactive relationship between inflammatory response activation, reduced neuronal functioning, and amyloid deposition. Furthermore cells associated with extracellular plaques within $\mathrm{AD}$ brains can produce a variety of cytokines, chemokines, and other related proteins that influence plaque and tangle formation [32].

There is strong evidence that inflammation exacerbates neuronal loss $[33,34]$. In fact, local inflammatory processes can exert a direct neurotoxicity, interfere with $\mathrm{A} \beta$ expression and metabolism, and maintain a chronic intracerebral acute phase protein secretion, which in turn favours formation of A $\beta$ oligomers [35].

On the other hand, microglial activation leads to an increased brain expression of major histocompatibility complex type II and an increased secretion of proinflammatory cytokines and chemokines such as interleukin-1 (IL-1), interleukin-6 (IL-6), tumour necrosis factor- $\alpha$ (TNF- $\alpha$ ), and interleukin-8 (IL-8), as well as complement components and acute phase proteins [36].

A "cytokine cycle" has been proposed where [37] the antiinflammatory cytokines (IL-4, IL-10, and IL-13) regulate A $\beta$ induced microglial/macrophage inflammatory responses and modify the microglial activity surrounding amyloid neuritic plaques [38]. Such cytokines can inhibit the induction of IL1 , TNF- $\alpha$, and MCP-1 in differentiated human monocytes and, above all, IL-10 causes dose-dependent inhibition of the IL- 6 secretion induced by $A \beta$ in these cells and in murine microglia [37].

Accordingly, several reports make it appears that the risk of $\mathrm{AD}$ is substantially influenced by polymorphisms in the promoter region and other untranslated regions, of genes encoding inflammatory mediators. Alleles that favour an increased or decreased expression of inflammatory mediators are more frequent in patients with $\mathrm{AD}$ than in controls [39].

$\mathrm{A} \beta$ has also been shown to induce a phagocytic response in microglia, suggesting a neuroprotective defense mechanism [40]. This is, however, coupled to an increased release of signalling molecules and reactive oxygen and nitrogen species, which may further promote neuronal damage [41].

Despite these findings, clinical trials of nonsteroidal antiinflammatory drugs (NSAIDs) in $\mathrm{AD}$ patients have been disappointing [42]. 
3.1. Peripheral Blood Mononuclear Cells. Nowadays it remains the need for a reliable, minimally invasive, and inexpensive biomarker for dementia, leading many to investigate peripheral blood. Blood collection is simple, inexpensive, and less invasive than lumbar puncture, allowing for repeated sampling. Approximately $500 \mathrm{~mL}$ of CSF is absorbed into the blood daily [43] and there is also evidence for blood-brain barrier (BBB) dysfunction in AD and other neurodegenerative disorders, which may enhance protein exchange between both fluids [44]. Consequently, the leakage of CNS metabolites into the peripheral system may reflect neurodegenerative disease status and could offer a suitable source of disease biomarkers.

$\mathrm{AD}$ also affects PBMCs that are defined as any blood cell with a round nucleus (i.e., lymphocytes, monocytes, or macrophages). These blood cells are a critical component of the immune system which provide defence against infection and respond to intruders. The lymphocyte population consists of CD4+ and CD8+ T cells, B cells and natural killer cells, CD14+ monocytes, basophils, neutrophils, eosinophils, and dendritic cells.

Although studies are continuously providing additional data that emphasize the central role of inflammation in $\mathrm{AD}$, PBMCs have not been sufficiently investigated in this context. Indeed, only scant studies have used PBMCs to measure cytokine release, showing a significantly different production of these inflammatory components in $\mathrm{AD}$ and MCI subjects compared to controls $[39,45]$ (Figure 1 ) as well as a greater IL1 and TNF- $\alpha$ production, associated with an increased risk of $\mathrm{AD}$, in elderly controls [46].

Delineating biochemical alterations in AD blood constituents may enable the identification of accessible footprints that mirror degenerative processes within the CNS.

Moreover PBMCs could reflect inflammatory mechanisms in a more specific way compared with the serum/plasma, and PBMC-associated biomarkers could thus provide novel insight into the pathogenesis of $\mathrm{AD}$.

In the following paragraphs we discuss the potential of PBMCs to serve as a peripheral laboratory to find molecular signatures in $\mathrm{AD}$ that could aid both in the differential diagnosis with other forms of dementia and in the monitoring of disease progression.

\section{Peptidyl-prolyl cis-/trans-Isomerase Pin 1 in PBMCs}

The peptidyl-prolyl cis-/trans-isomerase Pinl is a cytosolic protein that isomerizes the peptide bond of a phosphorylated serine or a phosphorylated threonine followed by a proline (pSer-/pThr-Pro). Pin1 catalyzes the cis-/trans-isomerization of its substrates, consequently potentiating the accessibility of the phosphate residue for further dephosphorylation by protein phosphatases such as the protein phosphatase PP2A. Alternatively, the binding of Pinl to other highly phosphorylated substrates can repress their dephosphorylation by calcineurin. Therefore, through isomerization of pSer/pThr-Pro, Pinl regulates the function or degradation of a growing number of proteins including transcription factors and cytoskeletal, mitotic, or proapoptotic proteins [47].
Pin1 consists of 2 functional domains. The binding domain corresponds to the amino-terminal region consisting of a group IV WW domain (Trp-Trp domain) that specifically binds to pSer-/pThr-Pro motifs. The carboxyl-terminal region is the catalytic domain [48]. Pinl substrate-binding and isomerase activity are regulated by phosphorylation. Indeed, 3 phosphorylation sites of Pin1 have been characterized. In particular, serine 16 is located in the WW domain and is phosphorylated by protein kinase A. Phosphorylation of Pinl at serine 16 represses substrate recognition [49]. Pinl has several additional putative phosphorylation sites (e.g., human Pin1 has 29 residues of serine or threonine and 3 tyrosines).

Phosphorylation of proteins is a key signalling mechanism in diverse of physiological and pathological processes. Pinl-catalysed conformational changes can have profound effects on phosphorylation signalling by regulating a spectrum of target activities. Interestingly, Pin1 deregulation is implicated in a number of conditions, notably ageing and age-related diseases, including cancer and AD. Pinl is overexpressed in most human cancers; it activates numerous oncogenes or growth enhancers and also inactivates a large number of tumour suppressors or growth inhibitors. By contrast, ablation of Pin1 prevents cancer but eventually leads to premature ageing and neurodegeneration. Recent studies have demonstrated the reemergence within the brain of cell cycle proteins as patients progress from MCI into AD. Pin1 plays an important role in regulating the activity of key proteins, such as CDK5, GSK3- $\beta$, and PP2A, that are involved not only in the cell cycle but also in the phosphorylation state of Tau [50].

Indeed, Pinl facilitates tau dephosphorylation [51] and regulates APP metabolism, thus providing additional support to the hypothesis that it has a neuroprotective function against AD [52-56].

It has been reported that Pinl activity is repressed by oxidation in AD [52-58] and that Pinl is localized to granular vesicles in AD and FTD but not to tau aggregates [55, 59-63].

It should be remarked that the expression and activity of Pinl are tightly regulated at a transcriptional level and that a Pinl gene polymorphism $(-842 \mathrm{G} / \mathrm{C})$ has been found to be associated with reduced levels of Pin1 in blood cells and with an increased risk for AD in an Italian cohort [64].

Interestingly, a depletion of the soluble form of Pin1 has been described in neurons from $\mathrm{AD}$ subjects [57,65] and differences in Pin 1 molecular and biochemical parameters have been reported in PBMCs from late-onset AD (LOAD) compared with control subjects [66].

In particular, in PBMCs from LOAD we observed a significant increase in Pinl gene expression together with a significant decrease in gene promoter methylation [66].

This latter finding holds particular relevance, since so far little is known about epigenetic patterns in AD. Moreover, epigenetic mechanisms have already been proposed as markers of AD in PBMC-derived DNA [67] and it has been claimed that DNA methylation in peripheral cells could be taken as a model of epigenetic gene regulation in the brain [68]. 


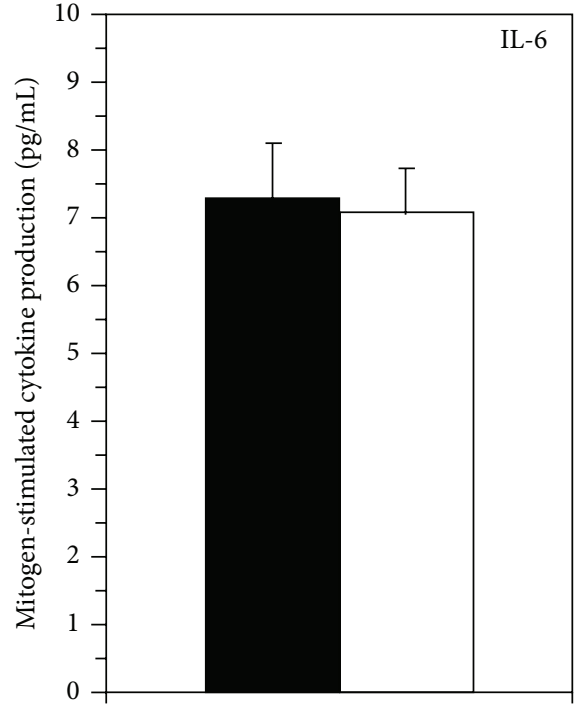

(a)

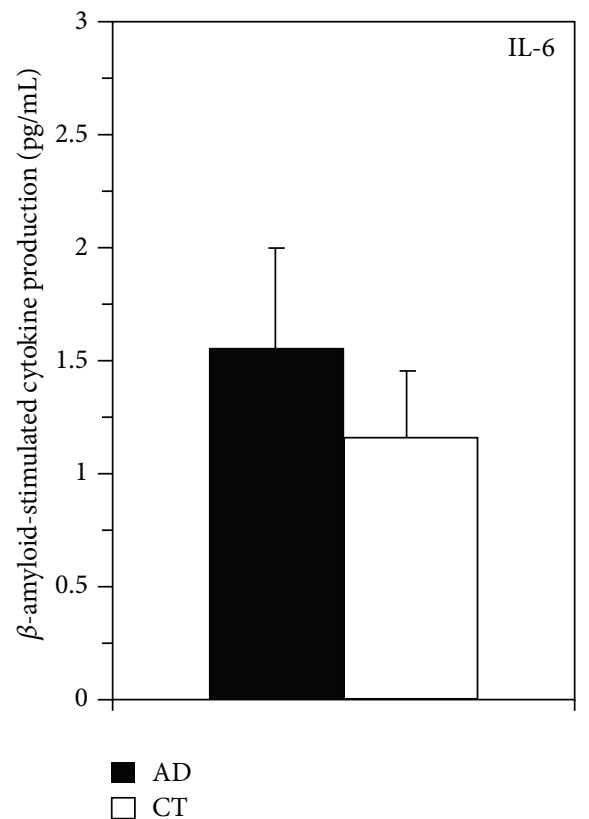

(c)

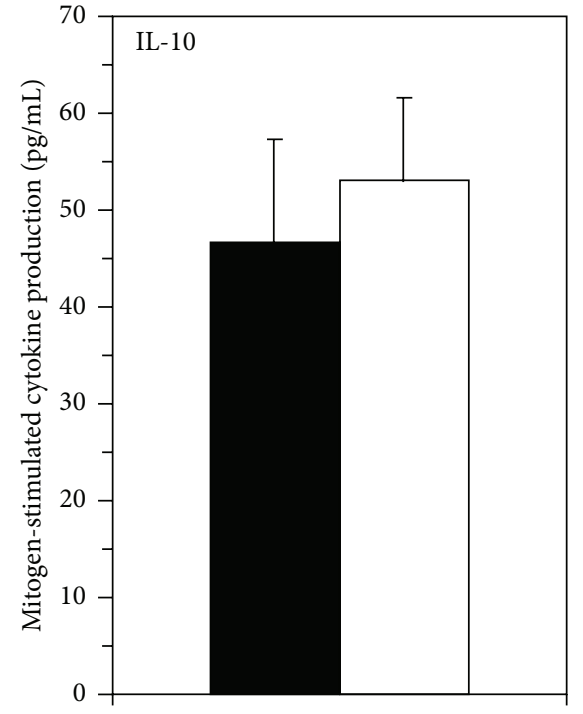

(b)

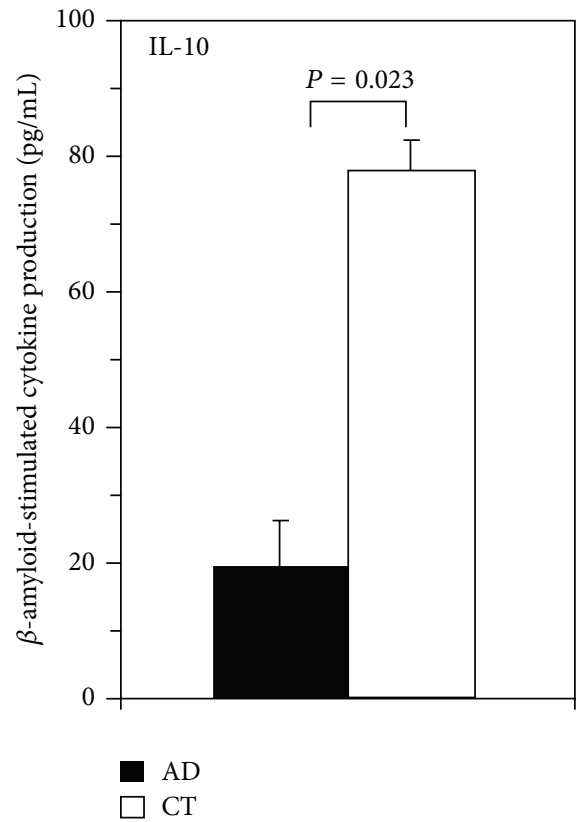

(d)

FIGURE 1: PBMCs of AD patients and age- and sex-matched controls (CT) were stimulated with a mitogen (LPS) and with a pool of three A $\beta$ peptides (A $\beta$ fragment 25-35; A $\beta$ fragment 1-40; A $\beta$ fragment 1-16). The production of IL-10 and IL-6 was measured by means of ELISA. There were no differences in mitogen-stimulated IL- 6 and IL-10 production in AD and controls. In contrast, when A $\beta$-stimulated production of IL- 6 and IL-10 was analysed, a marginally increased IL-6 production and a significantly decreased IL-10 generation were observed in AD patients compared to controls, suggesting an antigen-specific impairment in the production of these cytokines.

We have also shown that in LOAD subjects Ser $^{16}$ phosphorylation levels of Pinl were lower than in controls (Figure 2).

Phosphorylation of Pinl must therefore be a key factor in regulating its localization, function, and metabolism and tau seems to be involved in controlling the balance between the phosphorylation/dephosphorylation of Pinl in brain cellular lysate [69].

Moreover, Wang et al. [70] suggested that reduced Pin1 activity in the frontal cortex of patients with MCI contributes to the initial accumulation of hyperphosphorylated tau and is then followed, in a more advanced stage of the disease, by a compensatory upregulation of the Pinl gene that counteracts $\mathrm{A} \beta$ plaque formation.

In particular, with regard to our finding of lower Ser ${ }^{16}$ phosphorylation levels of Pinl in LOAD subjects relative to controls, different interpretations can be put forward: the presence in LOAD patients of rare gene variants of Pinl that could influence its phosphorylation state [71] and the effects on Pinl of a higher blood concentration of $\mathrm{A} \beta 42$ [72]. In 


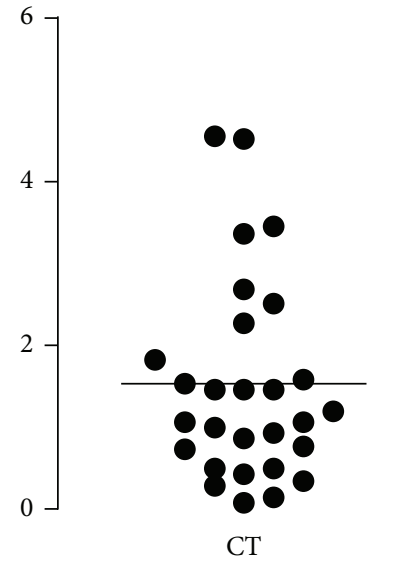

(a)

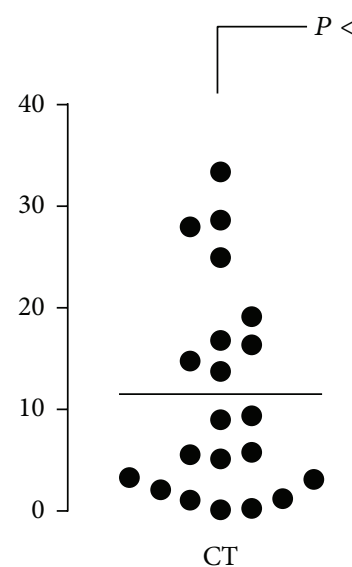

(c)
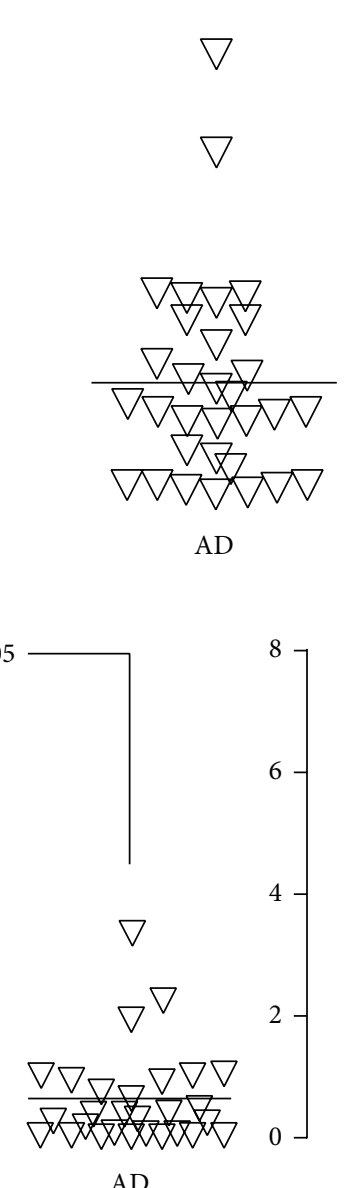

$\mathrm{AD}$

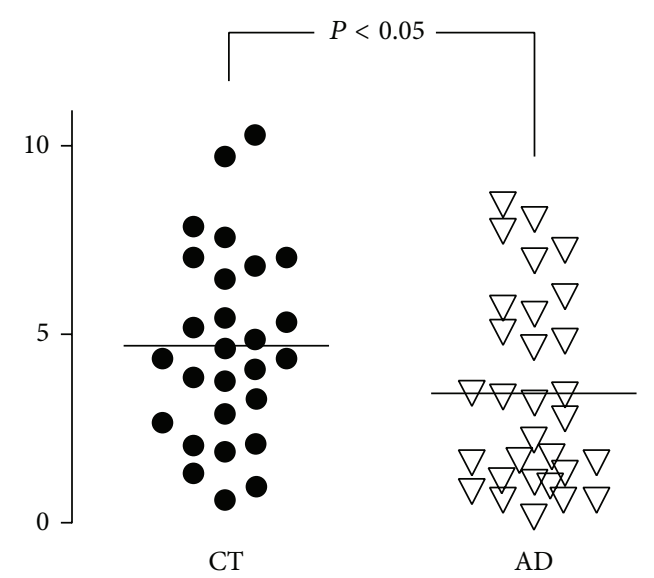

(b)

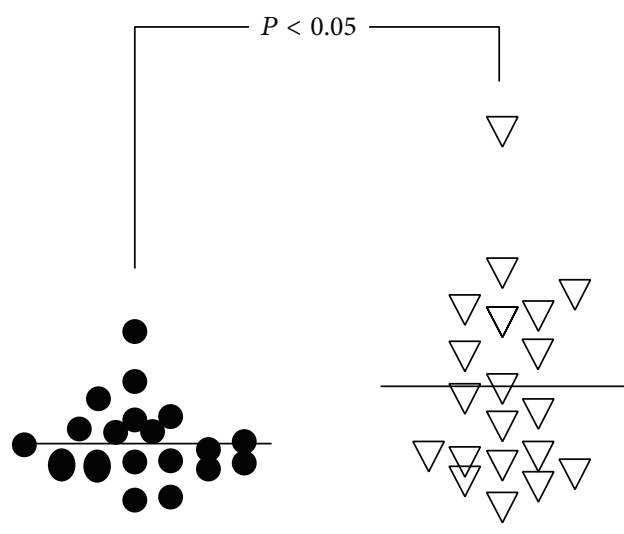

CT
$\mathrm{AD}$

(d)

FIGURE 2: Scatter dot plots showing the distributions of molecular and biochemical parameters of PBMCs from controls (CT) and LOAD: activity (a), Ser ${ }^{16}$ phosphorylation (b), methylation (c), and gene expression (d). The lines across the boxes indicate median values.

keeping with the latter hypothesis, in rat hippocampal cells, treatment with $\mathrm{A} \beta 42$ oligomers has been shown to promote a transient Pin1 dephosphorylation on $\operatorname{Ser}^{16}$ associated with a decrease in phosphorylated TauThr ${ }^{231}$ [73]. Whatever the specific explanation is, the modifications of Pinl observed in LOAD subjects make it reasonable to suppose that Pinl is involved in $\mathrm{AD}$ [74] and that epigenetic mechanisms (i.e., Pinl promoter methylation) play a role in the disease. Therefore, alterations in easily accessible peripheral cells may prove to be valuable biomarkers in the diagnosis and followup of $\mathrm{AD}$ and, potentially, also of some tauopathies.

\section{Epigenetics}

Literally meaning "above the genome" the epigenome comprises the heritable changes in gene expression that occur in the absence of changes to the DNA sequence itself. Epigenetic mechanisms include chromatin folding and attachment to the nuclear matrix, packaging of DNA around nucleosomes, covalent modifications of histone tails, and DNA methylation in the whole genome and/or in specific gene promoters [75].
DNA methylation, in particular, consists of the transfer of a methyl group to position 5 of the cytosine pyrimidine ring of a cytosine guanine dinucleotide $(\mathrm{CpG})$, which ultimately blocks the binding of transcription factors causing chromatin compaction and gene silencing [76].

The influence of regulatory small RNAs and microRNAs on gene transcription is also increasingly recognized as a key mechanism of epigenetic gene regulation [77].

Indeed, microRNAs (miRNAs), small regulatory RNAs in cells, probably constitute one of the most investigated extracellular RNAs in body fluidsand the levels of certain miRNAs in the circulation correlate well with different pathological conditions (i.e., miR-499 and miR-1 are associated with cardiovascular conditions) [78-81].

Epigenetic mechanisms are important in cell growth and differentiation [82]. Epigenetic change can be stochastic [83] or internally orchestrated as part of ageing [84]. Longitudinal changes in global and gene-specific DNA methylation clusters within families suggest there is a genetic control to methylation status [85].

Epigenetics is destined to change across the lifespan. In fact a loss of global DNA methylation and promoter 
hypermethylation of several specific genes occurs during ageing.

In particular ageing-associated DNA hypermethylation occurs predominantly in genes involved in the development of anatomical structures, organs, and multicellular organisms and in the regulation of transcription.

This phenomenon may be considered a new aspect of the age remodeling process, a continuous adaptation of the body to the deteriorative changes occurring over time. However, it is not clear how relevant these epigenetic changes are in the context of functional changes in gene expression [86].

Inappropriate epigenetic changes are associated with many diseases including cancer [87], Rett syndrome [88], Beckwith-Wiedemann syndrome [89], and other imprinting disorders.

Environmental signals can trigger epigenetic responses and may be an important mechanism by which environmental exposures are associated with disease [90]. Furthermore, epigenetic mechanisms may play an important role in the developmental origins of adult health and disease by providing a mechanism underlying the latent effects of adverse fetal, infant, and childhood environments on late-life chronic disease [91-93].

5.1. Epigenetic Epidemiology and Alzheimer's Disease. Epigenetic epidemiology is the study of the effects of heritable epigenetic changes on the occurrence and distribution of diseases in populations [94]. This research includes both transgenerational and intraindividual cellular epigenetic inheritance systems. Epigenetic changes are associated not only with ageing $[95,96]$, but also with psychiatric outcomes $[97,98]$ and neurodegeneration [99].

Evidence for the role of epigenetics in $\mathrm{AD}$ pathogenesis can be found in human studies of various tissues, in animal models, and in cell cultures [100-102]. Global changes associated with $\mathrm{AD}$ have been observed in DNA methylation, miRNAs, and histone modifications.

Discordant data have been reported on specific epigenetic modifications of tau- and amyloid-processing genes. On the one hand an altered regulation was reported across multiple brain regions [103-105], and on the other hand no differences were seen in DNA methylation in regions associated with MAPT, PSEN1, and APP [103].

Human postmortem case-control studies have demonstrated global hypomethylation in the entorhinal cortex of $\mathrm{AD}$ subjects [106] and in the temporal neocortex of an AD monozygotic twin relative to the cognitively normal twin [107].

An $\mathrm{AD}$ case-control study in the postmortem human parietal lobe cortex has revealed a differential regulation of several miRNAs, including miR-204, miR-211, and miR44691 [108].

Age-matched AD cases have been found to exhibit an increased neuronal global phosphorylation of histone 3 relative to controls, as determined by immunolabeling in the hippocampus, and such histone modification suggests mitotic activation [109].

In experiments where neuroblastoma cells were cultured under low folate and vitamin B12 conditions, PSEN1 and
BACE1 were hypomethylated, mRNA expression of BACE1 and PSEN1 was significantly induced, and $A \beta$ production was increased [110].

An additional study using human neuroblastoma cells and male rat brain tissue reports that APP mRNA expression is repressed by thyroid hormone (T3) sensitive histone modifications [111].

5.2. Epigenetics in PBMCs. The study of gene regulation in blood cells from living patients offers the possibility to go through the whole history of the disorder (including the response to pharmacological, metabolic, and environmental events) in a more comprehensive perspective, compared to postmortem studies which allow only pinpoint assessment.

It is important to note that PBMCs may also be a useful model of epigenetic gene regulation in the brain [68]. In fact, it has been shown that PBMCs share much of the nonsynaptic biochemical environment of neurons and contain the full complement of epigenetic enzymes found in most tissues, including neurons and peripheral nucleated cells $[112,113]$.

For instance, our group has investigated the role of DNA methylation in the PBMCS from LOAD subjects compared to controls and has demonstrated an altered Pin1 gene expression and promoter methylation [66], as detailed above, along with changes in fatty acid amide hydrolase (FAAH) and 5-lipoxygenases (5-LOX) genes (Faah EC 3.5.1.99 and Alox5 EC 1.13.11.34), proteins, and activity [114].

Also, by comparing DNA methylation of Faah and Alox 5 promoters we found a direct correlation between these two genes $[114,115]$.

It has been shown that oxygenation of the FAAH substrates by lipoxygenase activity modulates recognition of these molecules by their protein targets [116], with potential implications for their biological activity [117].

These results might suggest that a parallel increase of FAAH and 5-LOX expression in $\mathrm{AD}$ patients could evoke a sustained inflammatory condition, thus reinforcing neurodegeneration $[114,115]$.

This finding in peripheral cells is in agreement with previous results in postmortem AD brains [118], where FAAH protein upregulation within plaques was suggested to lead to an increase in metabolites from endocannabinoid anandamide (AEA) degradation (such as arachidonic acid). Such metabolites could contribute to the inflammatory process occurring in $\mathrm{AD}$.

Recently, there has been considerable interest in exploring the therapeutic potential of anti-inflammatory agents to prevent, treat, or slow down the progression of AD [119]. However, nonsteroidal anti-inflammatory drugs were found to be ineffective in $\mathrm{AD}$ patients with mild to moderate cognitive impairment [120], emphasizing the importance of an early diagnosis and therapy. Furthermore, pharmacological interventions based on chronic treatment with COX inhibitors, or treatment with anticytokine therapies, are not ideal for a long-term use, due to their gastrointestinal (COX1-selective inhibitors), cardiovascular (COX2-selective inhibitors), and immunosuppressive (anticytokine therapies) side effects [121]. 
Taken together, these lines of research converge towards the notion that novel anti-inflammatory targets may provide a safer strategy for the prevention and the treatment of AD. In such scenario PBMCs stand out as potential peripheral markers of disease within the CNS.

\section{Adenosine $A_{2 A}$ Receptors in PBMCs}

Nutritional alterations have been linked to the epigenetic modulation of some AD-related genes and seem to play a role in $\mathrm{AD}$ pathology. There is also evidence in favour of the epigenetic modulation of genes involved in the pathways activated by some dietary factors, both in ageing and disease, further supporting the involvement of epigenetic mechanisms in AD. A number of dietary elements have been reported to be either risk or protective factors for the development of $\mathrm{AD}$. These include fat, fatty acids, antioxidants, fish, vitamins, alcohol, and, more recently, caffeine [122].

The neuroprotective effect of caffeine consumption on AD pathology is currently emerging from both basic and epidemiological studies [123]. In vitro and animal studies have provided convincing data on caffeine's neuroprotective effects against and in the presence of AD pathology [124-126]. Human studies have begun to demonstrate the presence of a similar neuroprotective role in the ageing and demented population.

However, due to the conflicting results from some longitudinal studies, there is no consensus about the role of caffeine in the onset of AD [124-128].

Caffeine is one of the most consumed psychoactive drugs and acts mostly by blocking adenosine receptors [129]. The purine ribonucleoside adenosine (Ado) is a naturally occurring metabolite that is ubiquitously distributed throughout the body as a metabolic intermediary. Intra- and extracellular Ado levels rise in response to physiological stimuli and with metabolic/energetic perturbations, inflammatory challenges, and tissue injury $[130,131]$.

The physiological responses to Ado take place as a result of the binding and activation of different transmembrane receptors: the high-affinity $A_{1}$ and $A_{2 A}\left(A_{2 A}\right)$ receptors, the low-affinity $A_{2 B}$ receptor, or the low-abundance $A_{3}$ receptor [132].

These receptors are G-protein coupled receptors that regulate, in opposite directions, the second messenger cAMP; while $A_{1}$ is inhibitory Gi-coupled, $A_{2 A}$ is excitatory Gscoupled, thereby decreasing and increasing cAMP levels, respectively [133]. The activation of these receptors is also able to modulate $\mathrm{Ca}^{2+}$ channels and the phospholipase $\mathrm{C}$ pathway. Through these actions and by modulating both the release and the uptake of different neurotransmitters, the balance between the activation of adenosine $A_{1}$ and $A_{2 A}$ receptors allows the fine tuning of synaptic transmission and plasticity in the hippocampus [134].

In particular $\mathrm{A}_{2 \mathrm{~A}}$ is present in a wide variety of tissues, including the nervous system and the peripheral immune system, where they display different levels of expression: significant levels in neurons and peripheral cells (lymphocytes and neutrophils) and lower levels in glial cells [132].
The different levels of expression of $\mathrm{A}_{2 \mathrm{~A}}$ in different tissues are consistent with the sophisticated, multifaceted neurochemical, and molecular effects of the Ado system. On the basis of in vitro $[135,136]$ and in vivo [137] studies, it has become clear that $\mathrm{A}_{2 \mathrm{~A}}$, through complex mechanisms which are still poorly understood [138-141], plays a critical role in the modulation of inflammatory reactions, influencing functional outcome in a broad spectrum of pathologies including neurodegeneration [142, 143].

Moreover it has been demonstrated that $\mathrm{A}_{2 \mathrm{~A}}$ is able to prevent $\mathrm{A} \beta$-induced synaptotoxicity in animal models and cell cultures [144] and it has been shown to control NMDA currents and glutamate outflow in the hippocampus [145, 146].

Contrasting data have been reported so far on the beneficial/detrimental effects of $A_{2 A}$ on brain cells [147]. The blockade of $\mathrm{A}_{2 \mathrm{~A}}$ alleviates the long-term burden of brain disorders such as ischaemia, epilepsy, Parkinson's disease, or $\operatorname{AD}[138,145,148,149]$. On the other hand, agonists of $A_{2 A}$ can protect the CNS against several insults, including ischemia and excitotoxins $[143,150]$.

In the periphery $\mathrm{A}_{2 \mathrm{~A}}$ contributes to coronary endothelial dilatation in mice [151], can inhibit endothelial apoptosis [152], and preserves vascular reactivity following hemorrhagic shock in rats [153].

We recently investigated $A_{2 A}$ gene expression and density in the PBMCs of patients with amnestic MCI (a-MCI), multiple cognitive domain MCI (mcd-MCI), outright $\mathrm{AD}, \mathrm{VD}$, and controls. We found that $A_{2 A}$ expression is upregulated in the peripheral cells of a-MCI but not AD subjects, supporting an involvement of the Ado system in the early stages of AD [154]. We also showed that $A_{2 A}$ expression is lower in the PBMCs of subjects with VD than $\mathrm{AD}$, highlighting its possible relevance as a biomarker that may help differentiate two forms of dementia that are often closely associated (Figure 3 ).

Indeed, ROC analysis data showed that $\mathrm{A}_{2 \mathrm{~A}}$ possesses a moderate degree of sensitivity and specificity for identifying VD patients from a heterogeneous group composed of VD and $\mathrm{AD}$ patients. The lower $\mathrm{A}_{2 \mathrm{~A}}$ expression in $\mathrm{VD}$ compared to $\mathrm{AD}$ subjects seems to suggest a differential role of the Ado system in these dementias [155].

The methylation of the ADORA2A promoter gene, which codes for $A_{2 A}$, may explain its different expression in these pathological conditions as well as in the ageing process, as already mentioned [156].

Moreover, $\mathrm{A}_{2 \mathrm{~A}}$ represents the main Ado receptor involved in inflammation and it is interesting to note that also other inflammatory biomarkers are differently expressed in VD and $\mathrm{AD}$ subjects, such as alphal-globulin and alpha2-globulin in the serum [157] and C3a and C4a in the CSF [158].

On the other hand the decreased $\mathrm{A}_{2 \mathrm{~A}}$ levels in VD could be a defence mechanism since it has been demonstrated that pharmacologic inactivation or genetic deletion of $\mathrm{A}_{2 \mathrm{~A}} \mathrm{R}$ reduces neuronal injury after global and focal cerebral ischemia in many animal models $[149,159,160]$. From our results it can be concluded that $\mathrm{A}_{2 \mathrm{~A}}$ may play an important but differential role in both types of dementia: its upregulation in the preclinical stages of $\mathrm{AD}$ could counterbalance the existing inflammatory state and its downregulation in 


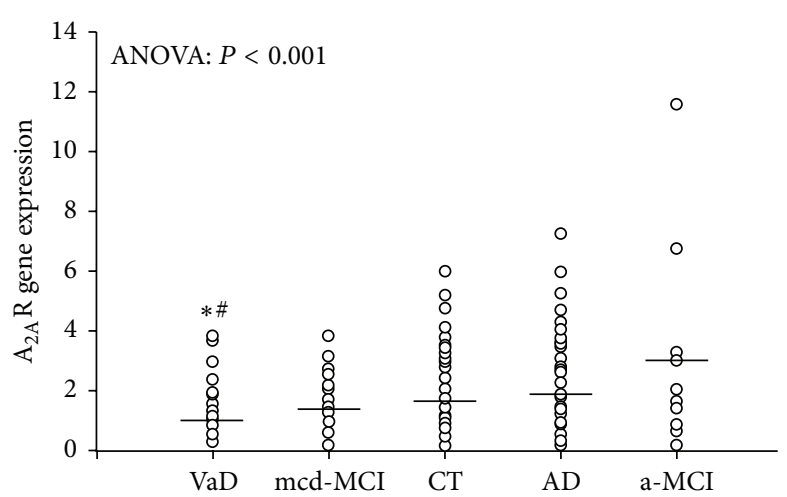

(a)

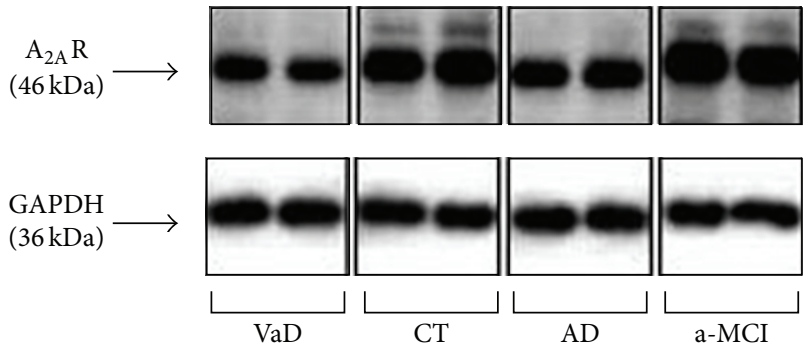

(b)

Figure 3: (a) Scatter plot of $\mathrm{A}_{2 \mathrm{~A}}$ gene expression in PBMCs from VD, mcd-MCI, controls (CT), AD, and a-MCI subjects (the lines represent the mean value for each group). ${ }^{*} P<0.001$ versus $\mathrm{AD} ;{ }^{\#} P<0.05$ versus a-MCI. (b) Representative picture of the western blot analysis of the $\mathrm{A}_{2 \mathrm{~A}}$ densities in PBMCs extracts, running in duplicate, from one subject from the VD, CT, $\mathrm{AD}$, and a-MCI groups, respectively.

VD could reflect the effects of $\mathrm{A}_{2 \mathrm{~A}}$ on the brain vasculature [161]. It can therefore be suggested that $A_{2 A}$ could serve as a biomarker in the differential diagnosis between $\mathrm{VD}$ and $\mathrm{AD}$.

\section{Conclusions}

Peripheral cells and in particular PBMCs seem to directly participate to neurodegenerative processes. They play critical roles in immune response, metabolism, and communication with other cells as already pointed out many years ago [162]. Moreover, PBMCs have been shown to share much of the nonsynaptic biochemical environment of neurons and contain the full complement of epigenetic enzymes and machinery, which are found in both neurons and peripheral nucleated cells, as in most other tissues.

The substantial evidence in favour of the notion that PBMCs provide a window into the CNS holds particular relevance in neurodegenerative disorders in which, unlike most other diseases, the affected tissue is not directly accessible to evaluation. On a final note, it should be mentioned that the value of biochemical dysfunctions in PBMCs as mirrors of CNS defects appears to extend well beyond dementia.For instance, FAAH and other elements of the endocannabinoid system show alterations in the blood that resemble those within the CNS in a broad spectrum of clinical conditions including Parkinson's and Huntington's disease, multiple sclerosis, schizophrenia, minor depression, and headache [163].

Nowadays we do not know if PBMCs biomarkers are better or worse than the CSF biomarkers. Our study is only a preliminary study, instead multiple studies have examined CSF to establish sensitivity and specificity of CSF biomarkers. Moreover, despite these many studies, a large variability exists in the literature as to CSF biomarker diagnostic accuracies and cut-offs. As biomarker discovery in PBMCs is an ongoing process and PBMCs biomarkers are still immature, we need further analysis to enlarge design population.

It will be also of relevance the possibility to utilize intracellular biomarkers in specific blood cell subpopulations.
In fact the differences in between subjects could also be due to different composition of their PBMCs pools, even if separating PBMCs into subpopulations would not permit the cell-cell interactions required for activation of lymphocytes.

Finally, we assume that the combination of peripheral and CSF markers may be utilized to categorize patients since early stages of dementia and to understand mechanisms underlying dementia.

\section{Conflict of Interests}

The authors declare that there is no conflict of interests regarding the publication of this paper.

\section{References}

[1] D. E. Barnes and K. Yaffe, "The projected effect of risk factor reduction on Alzheimer's disease prevalence," The Lancet Neurology, vol. 10, no. 9, pp. 819-828, 2011.

[2] P. B. Gorelick, A. Scuteri, S. E. Black et al., "Vascular contributions to cognitive impairment and dementia: a statement for healthcare professionals from the American Heart Association/American Stroke Association," Stroke, vol. 42, no. 9, pp. 2672-2713, 2011.

[3] L. Fratiglioni, L. J. Launer, K. Andersen et al., "Incidence of dementia and major subtypes in Europe: a collaborative study of population-based cohorts," Neurology, vol. 54, supplement 11, pp. S10-S15, 2000.

[4] L. Battistin and A. Cagnin, "Vascular cognitive disorder. A biological and clinical overview," Neurochemical Research, vol. 35, no. 12, pp. 1933-1938, 2010.

[5] K. A. Jellinger, "The enigma of vascular cognitive disorder and vascular dementia," Acta Neuropathologica, vol. 113, no. 4, pp. 349-388, 2007.

[6] C. Iadecola, "Neurovascular regulation in the normal brain and in Alzheimer's disease," Nature Reviews Neuroscience, vol. 5, no. 5, pp. 347-360, 2004.

[7] B. V. Zlokovic, "New therapeutic targets in the neurovascular pathway in Alzheimer's disease," Neurotherapeutics, vol. 5, no. 3, pp. 409-414, 2008. 
[8] J. Atkinson, W. A. Colburn, V. G. DeGruttola et al., "Biomarkers and surrogate endpoints: preferred definitions and conceptual framework," Clinical Pharmacology and Therapeutics, vol. 69, no. 3, pp. 89-95, 2001.

[9] J.-C. Tardif, T. Heinonen, D. Orloff, and P. Libby, "Vascular biomarkers and surrogates in cardiovascular disease," Circulation, vol. 113, no. 25, pp. 2936-2942, 2006.

[10] V. O. Puntmann, "How-to guide on biomarkers: biomarker definitions, validation and applications with examples from cardiovascular disease," Postgraduate Medical Journal, vol. 85, no. 1008, pp. 538-545, 2009.

[11] A. Wade, "Derivation versus validation," Archives of Disease in Childhood, vol. 83, no. 6, pp. 459-460, 2000.

[12] C. Lausted, I. Lee, Y. Zhou et al., "Systems approach to neurodegenerative disease biomarker discovery," Annual Review of Pharmacology and Toxicology, vol. 54, pp. 457-481, 2014.

[13] G. McKhann, D. Drachman, and M. Folstein, "Clinical diagnosis of Alzheimer's disease: report of the NINCDS-ADRDA work group under the auspices of Department of Health and Human Services Task Force on Alzheimer's disease," Neurology, vol. 34, no. 7, pp. 939-944, 1984.

[14] B. Dubois, H. H. Feldman, C. Jacova et al., "Research criteria for the diagnosis of Alzheimer's disease: revising the NINCDSADRDA criteria," The Lancet Neurology, vol. 6, no. 8, pp. 734746, 2007.

[15] J. Wiltfang, H. Esselmann, M. Bibl et al., "Amyloid $\beta$ peptide ratio $42 / 40$ but not $\mathrm{A} \beta 42$ correlates with phospho-Tau in patients with low- and high-CSF A $\beta 40$ load," Journal of Neurochemistry, vol. 101, no. 4, pp. 1053-1059, 2007.

[16] G. Farias, P. Perez, A. Slachevsky, and R. B. Maccioni, "Platelet tau pattern correlates with cognitive status in Alzheimer's disease," Journal of Alzheimer's Disease, vol. 31, no. 1, pp. 65-69, 2012.

[17] K. Neumann, G. Farías, A. Slachevsky, P. Perez, and R. B. MacCioni, "Human platelets tau: a potential peripheral marker for Alzheimer's disease," Journal of Alzheimer's Disease, vol. 25, no. 1, pp. 103-109, 2011.

[18] C. Hooper, S. Lovestone, and R. Sainz-Fuertes, "Alzheimer's disease, diagnosis and the need for biomarkers," Biomarker Insights, vol. 2008, no. 3, pp. 317-323, 2008.

[19] R. C. Petersen, G. E. Smith, S. C. Waring, R. J. Ivnik, E. G. Tangalos, and E. Kokmen, "Mild cognitive impairment: clinical characterization and outcome," Archives of Neurology, vol. 56, no. 3, pp. 303-308, 1999.

[20] A. Simmons, E. Westman, S. Muehlboeck et al., "The AddNeuroMed framework for multi-centre MRI assessment of Alzheimer's disease: experience from the first 24 months," International Journal of Geriatric Psychiatry, vol. 26, no. 1, pp. 75-82, 2011.

[21] M. J. de Leon, S. Desanti, R. Zinkowski et al., "MRI and CSF studies in the early diagnosis of Alzheimer's disease," Journal of Internal Medicine, vol. 256, no. 3, pp. 205-223, 2004.

[22] H. Hampel, K. Bürger, S. J. Teipel, A. L. W. Bokde, H. Zetterberg, and K. Blennow, "Core candidate neurochemical and imaging biomarkers of Alzheimer's disease," Alzheimer's and Dementia, vol. 4, no. 1, pp. 38-48, 2008.

[23] R. Craig-Schapiro, A. M. Fagan, and D. M. Holtzman, "Biomarkers of Alzheimer's disease," Neurobiology of Disease, vol. 35, no. 2, pp. 128-140, 2009.
[24] J. C. Morris, C. M. Roe, E. A. Grant et al., "Pittsburgh compound B imaging and prediction of progression from cognitive normality to symptomatic Alzheimer disease," Archives of Neurology, vol. 66, no. 12, pp. 1469-1475, 2009.

[25] R. J. Perrin, A. M. Fagan, and D. M. Holtzman, "Multimodal techniques for diagnosis and prognosis of Alzheimer's disease," Nature, vol. 461, no. 7266, pp. 916-922, 2009.

[26] A. Maddalena, A. Papassotiropoulos, B. Müller-Tillmanns et al., "Biochemical diagnosis of Alzheimer disease by measuring the cerebrospinal fluid ratio of phosphorylated tau protein to $\beta$ amyloid peptide42," Archives of Neurology, vol. 60, no. 9, pp. 1202-1206, 2003.

[27] G. de Meyer, F. Shapiro, H. Vanderstichele et al., "Diagnosisindependent Alzheimer disease biomarker signature in cognitively normal elderly people," Archives of Neurology, vol. 67, no. 8, pp. 949-956, 2010.

[28] P. J. Visser, F. Verhey, D. L. Knol et al., "Prevalence and prognostic value of CSF markers of Alzheimer's disease pathology in patients with subjective cognitive impairment or mild cognitive impairment in the DESCRIPA study: a prospective cohort study," The Lancet Neurology, vol. 8, no. 7, pp. 619-627, 2009.

[29] M. Ingelson, M. Blomberg, E. Benedikz et al., "Tau immunoreactivity detected in human plasma, but no obvious increase in dementia," Dementia and Geriatric Cognitive Disorders, vol. 10, no. 6, pp. 442-445, 1999.

[30] N. Mattsson, E. Roseń, O. Hansson et al., "Age and diagnostic performance of Alzheimer disease CSF biomarkers," Neurology, vol. 78, no. 7, pp. 468-476, 2012.

[31] N. S. M. Schoonenboom, F. E. Reesink, N. A. Verwey et al., "Cerebrospinal fluid markers for differential dementia diagnosis in a large memory clinic cohort," Neurology, vol. 78, no. 1, pp. 47-54, 2012.

[32] M. Hüll, K. Lieb, and B. L. Fiebich, "Pathways of inflammatory activation in Alzheimer's disease: potential targets for disease modifying drugs," Current Medicinal Chemistry, vol. 9, no. 1, pp. 83-88, 2002.

[33] E. G. McGeer and P. L. McGeer, "Innate immunity in Alzheimer's disease: a model for local inflammatory reactions," Molecular Interventions, vol. 1, no. 1, pp. 22-29, 2001.

[34] E. G. McGeer and P. L. McGeer, "Chronic inflammation in Alzheimer's disease offers therapeutic opportunities," Expert Review of Neurotherapeutics, vol. 1, no. 1, pp. 53-60, 2001.

[35] F. Licastro and M. Chiappelli, "Brain immune responses cognitive decline and dementia: relationship with phenotype expression and genetic background," Mechanisms of Ageing and Development, vol. 124, no. 4, pp. 539-548, 2003.

[36] J. Rogers and L.-F. Lue, "Microglial chemotaxis, activation, and phagocytosis of amyloid $\beta$-peptide as linked phenomena in Alzheimer's disease," Neurochemistry International, vol. 39, no. 5-6, pp. 333-340, 2001.

[37] A. M. Szczepanik, S. Funes, W. Petko, and G. E. Ringheim, "IL-4, IL-10 and IL-13 modulate A $\beta(1-42)$-induced cytokine and chemokine production in primary murine microglia and a human monocyte cell line," Journal of Neuroimmunology, vol. 113, no. 1, pp. 49-62, 2001.

[38] C. C. Chao, T. W. Molitor, and S. Hu, "Neuroprotective role of IL-4 against activated microglia," Journal of Immunology, vol. 151, no. 3, pp. 1473-1481, 1993.

[39] B. Arosio, D. Trabattoni, L. Galimberti et al., "Interleukin10 and interleukin-6 gene polymorphisms as risk factors for Alzheimer's disease," Neurobiology of Aging, vol. 25, no. 8, pp. 1009-1015, 2004. 
[40] E. E. Tuppo and H. R. Arias, "The role of inflammation in Alzheimer's disease," International Journal of Biochemistry and Cell Biology, vol. 37, no. 2, pp. 289-305, 2005.

[41] C. Holmes and J. Butchart, "Systemic inflammation and Alzheimer's disease," Biochemical Society Transactions, vol. 39, no. 4, pp. 898-901, 2011.

[42] P. L. McGeer and E. G. McGeer, "NSAIDs and Alzheimer disease: epidemiological, animal model and clinical studies," Neurobiology of Aging, vol. 28, no. 5, pp. 639-647, 2007.

[43] A. Hye, S. Lynham, M. Thambisetty et al., "Proteome-based plasma biomarkers for Alzheimer's disease," Brain, vol. 129, part 11, pp. 3042-3050, 2006.

[44] D. J. Begley, "Delivery of therapeutic agents to the central nervous system: the problems and the possibilities," Pharmacology and Therapeutics, vol. 104, no. 1, pp. 29-45, 2004.

[45] R. J. Guerreiro, I. Santana, J. M. Brás, B. Santiago, A. Paiva, and C. Oliveira, "Peripheral inflammatory cytokines as biomarkers in Alzheimer's disease and mild cognitive impairment," Neurodegenerative Diseases, vol. 4, no. 6, pp. 406-412, 2007.

[46] Z. S. Tan, A. S. Beiser, R. S. Vasan et al., "Inflammatory markers and the risk of Alzheimer disease: the Framingham study," Neurology, vol. 68, no. 22, pp. 1902-1908, 2007.

[47] P. Rudrabhatla and H. C. Pant, "Phosphorylation-specific peptidyl-prolyl isomerization of neuronal cytoskeletal proteins by pin1: implications for therapeutics in neurodegeneration," Journal of Alzheimer's Disease, vol. 19, no. 2, pp. 389-403, 2010.

[48] G. Wulf, G. Finn, F. Suizu, and K. P. Lu, "Phosphorylationspecific prolyl isomerization: is there an underlying theme?" Nature Cell Biology, vol. 7, no. 5, pp. 435-441, 2005.

[49] P.-J. Lu, X. Z. Zhou, Y.-C. Liou, J. P. Noel, and K. P. Lu, "Critical role of WW domain phosphorylation in regulating phosphoserine binding activity and Pinl function," Journal of Biological Chemistry, vol. 277, no. 4, pp. 2381-2384, 2002.

[50] L. Pastorino, S. L. Ma, M. Balastik et al., "Alzheimer's diseaserelated loss of Pinl function influences the intracellular localization and the processing of AbetaPP .," Journal of Alzheimer's Disease, vol. 30, no. 2, pp. 277-297, 2012.

[51] X. Z. Zhou, O. Kops, A. Werner et al., "Pin1-dependent prolyl isomerization regulates dephosphorylation of Cdc25C and Tau proteins," Molecular Cell, vol. 6, no. 4, pp. 873-883, 2000.

[52] M.-C. Galas, P. Dourlen, S. Bégard et al., “The peptidylprolyl cis/trans-isomerase Pin1 modulates stress-induced dephosphorylation of Tau in neurons: implication in a pathological mechanism related to Alzheimer disease," Journal of Biological Chemistry, vol. 281, no. 28, pp. 19296-19304, 2006.

[53] M. Hamdane, P. Dourlen, A. Bretteville et al., "Pin1 allows for differential Tau dephosphorylation in neuronal cells," Molecular and Cellular Neuroscience, vol. 32, no. 1-2, pp. 155-160, 2006.

[54] Y.-C. Liou, A. Sun, A. Ryo et al., "Role of the prolyl isomerase Pinl in protecting against age-dependent neurodegeneration," Nature, vol. 424, no. 6948, pp. 556-561, 2003.

[55] P.-J. Lu, G. Wulf, X. Z. Zhou, P. Davies, and K. P. Lu, “The prolyl isomerase Pinl restores the function of Alzheimer-associated phosphorylated tau protein," Nature, vol. 399, no. 6738, pp. 784788, 1999.

[56] L. Pastorino, A. Sun, P. J. Lu et al., "The prolyl isomerase Pin1 regulates amyloid precursor protein processing and amyloidbeta production," Nature, vol. 440, no. 7083, pp. 528-534, 2006.

[57] D. A. Butterfield, H. M. Abdul, W. Opii et al., "Pin1 in Alzheimer's disease," Journal of Neurochemistry, vol. 98, no. 6, pp. 1697-1706, 2006.
[58] R. Sultana, D. Boyd-Kimball, H. F. Poon et al., "Oxidative modification and down-regulation of Pinl in Alzheimer's disease hippocampus: a redox proteomics analysis," Neurobiology of Aging, vol. 27, no. 7, pp. 918-925, 2006.

[59] A. Dakson, O. Yokota, M. Esiri et al., "Granular expression of prolyl-peptidyl isomerase PIN1 is a constant and specific feature of Alzheimer's disease pathology and is independent of tau, $\mathrm{A} \beta$ and TDP-43 pathology," Acta Neuropathologica, vol. 121, no. 5, pp. 635-649, 2011.

[60] M. Holzer, U. Gärtner, A. Stöbe et al., "Inverse association of Pinl and tau accumulation in Alzheimer's disease hippocampus," Acta Neuropathologica, vol. 104, no. 5, pp. 471-481, 2002.

[61] P. Ramakrishnan, D. W. Dickson, and P. Davies, "Pinl colocalization with phosphorylated tau in Alzheimer's disease and other tauopathies," Neurobiology of Disease, vol. 14, no. 2, pp. 251-564, 2003.

[62] J. R. Thorpe, S. J. Morley, and S. L. Rulten, "Utilizing the peptidyl-prolyl cis-trans isomerase Pinl as a probe of its phosphorylated target proteins: examples of binding to nuclear proteins in a human kidney cell line and to tau in Alzheimer's diseased brain," Journal of Histochemistry and Cytochemistry, vol. 49, no. 1, pp. 97-108, 2001.

[63] J. R. Thorpe, S. Mosaheb, L. Hashemzadeh-Bonehi et al., "Shortfalls in the peptidyl-prolyl cis-trans isomerase protein Pinl in neurons are associated with frontotemporal dementias," Neurobiology of Disease, vol. 17, no. 2, pp. 237-249, 2004.

[64] L. Segat, A. Pontillo, G. Annoni et al., "PIN1 promoter polymorphisms are associated with Alzheimer's disease," Neurobiology of Aging, vol. 28, no. 1, pp. 69-74, 2007.

[65] D. A. Butterfield, H. F. Poon, D. St. Clair et al., "Redox proteomics identification of oxidatively modified hippocampal proteins in mild cognitive impairment: insights into the development of Alzheimer's disease," Neurobiology of Disease, vol. 22, no. 2, pp. 223-232, 2006.

[66] B. Arosio, A. Bulbarelli, S. Bastias Candia et al., "Pinl contribution to Alzheimer's disease: transcriptional and epigenetic mechanisms in patients with late-onset Alzheimer's disease," Neurodegenerative Diseases, vol. 10, no. 1-4, pp. 207-211, 2012.

[67] S. Ray, M. Britschgi, C. Herbert et al., "Classification and prediction of clinical Alzheimer's diagnosis based on plasma signaling proteins," Nature Medicine, vol. 13, no. 11, pp. 13591362, 2007.

[68] D. P. Gavin and R. P. Sharma, "Histone modifications, DNA methylation, and Schizophrenia," Neuroscience and Biobehavioral Reviews, vol. 34, no. 6, pp. 882-888, 2010.

[69] K. Ando, P. Dourlen, A. V. Sambo et al., “Tau pathology modulates Pin1 post-translational modifications and may be relevant as biomarker," Neurobiology of Aging, vol. 34, no. 3, pp. 757-769, 2013.

[70] S. Wang, B. P. Simon, D. A. Bennett, J. A. Schneider, J. S. Malter, and D.-S. Wang, "The significance of Pin1 in the development of Alzheimer's disease," Journal of Alzheimer's Disease, vol. 11, no. 1, pp. 13-23, 2007.

[71] A. Maruszak, K. Safranow, K. Gustaw et al., "PIN1 gene variants in Alzheimer's disease," BMC Medical Genetics, vol. 10, article $115,2009$.

[72] D. Storace, S. Cammarata, R. Borghi et al., "Elevation of $\beta$ amyloid 1-42 autoantibodies in the blood of amnestic patients with mild cognitive impairment," Archives of Neurology, vol. 67, no. 7, pp. 867-872, 2010.

[73] A. Bulbarelli, E. Lonati, E. Cazzaniga, M. Gregori, and M. Masserini, "Pinl affects Tau phosphorylation in response to $\mathrm{A} \beta$ 
oligomers," Molecular and Cellular Neuroscience, vol. 42, no. 1, pp. 75-80, 2009.

[74] E. Lonati, M. Masserini, and A. Bulbarelli, "Pinl: a new outlook in alzheimer's disease," Current Alzheimer Research, vol. 8, no. 6, pp. 615-622, 2011.

[75] K. M. Bakulski, L. S. Rozek, D. C. Dolinoy, H. L. Paulson, and H. $\mathrm{Hu}$, "Alzheimer's disease and environmental exposure to lead: the epidemiologic evidence and potential role of epigenetics," Current Alzheimer Research, vol. 9, no. 5, pp. 563-573, 2012.

[76] R. Pidsley and J. Mill, "Epigenetic studies of psychosis: current findings, methodological approaches, and implications for postmortem research," Biological Psychiatry, vol. 69, no. 2, pp. 146-156, 2011.

[77] K. V. Morris, "The emerging role of RNA in the regulation of gene transcription in human cells," Seminars in Cell and Developmental Biology, vol. 22, no. 4, pp. 351-358, 2011.

[78] O. Gidlöf, P. Andersson, J. van der Pals, M. Götberg, and D. Erlinge, "Cardiospecific microRNA plasma levels correlate with troponin and cardiac function in patients with ST elevation myocardial infarction, are selectively dependent on renal elimination, and can be detected in urine samples," Cardiology, vol. 118, no. 4, pp. 217-226, 2011.

[79] Y. Kuwabara, K. Ono, T. Horie et al., "Increased microRNA1 and microRNA-133a levels in serum of patients with cardiovascular disease indicate myocardial damage," Circulation: Cardiovascular Genetics, vol. 4, no. 4, pp. 446-454, 2011.

[80] P. S. Mitchell, R. K. Parkin, E. M. Kroh et al., "Circulating microRNAs as stable blood-based markers for cancer detection," Proceedings of the National Academy of Sciences of the United States of America, vol. 105, no. 30, pp. 10513-10518, 2008.

[81] K. Wang, S. Zhang, B. Marzolf et al., "Circulating microRNAs, potential biomarkers for drug-induced liver injury," Proceedings of the National Academy of Sciences of the United States of America, vol. 106, no. 11, pp. 4402-4407, 2009.

[82] P. A. Jones and S. M. Taylor, "Cellular differentiation, cytidine analogs and DNA methylation," Cell, vol. 20, no. 1, pp. 85-93, 1980.

[83] A. P. Feinberg and R. A. Irizarry, "Stochastic epigenetic variation as a driving force of development, evolutionary adaptation, and disease," Proceedings of the National Academy of Sciences of the United States of America, vol. 107, supplement 1, pp. 1757-1764, 2010.

[84] M. F. Fraga and M. Esteller, "Epigenetics and aging: the targets and the marks," Trends in Genetics, vol. 23, no. 8, pp. 413-418, 2007.

[85] H. T. Bjornsson, M. I. Sigurdsson, M. D. Fallin et al., "Intraindividual change over time in DNA methylation with familial clustering," Journal of the American Medical Association, vol. 299, no. 24, pp. 2877-2883, 2008.

[86] D. Gentilini, D. Mari, D. Castaldi et al., "Role of epigenetics in human aging and longevity: genome-wide DNA methylation profile in centenarians and centenarians' offspring," Age, vol. 35, no. 5, pp. 1961-1973, 2013.

[87] M. Esteller, "Molecular origins of cancer: epigenetics in cancer," The New England Journal of Medicine, vol. 358, no. 11, pp. 11481059, 2008.

[88] S.-I. Horike, S. Cai, M. Miyano, J.-F. Cheng, and T. KohwiShigematsu, "Loss of silent-chromatin looping and impaired imprinting of DLX5 in Rett syndrome," Nature Genetics, vol. 37, no. 1, pp. 31-40, 2005.
[89] M. R. DeBaun, E. L. Niemitz, D. E. McNeil, S. A. Brandenburg, M. P. Lee, and A. P. Feinberg, "Epigenetic alterations of H19 and LIT1 distinguish patients with Beckwith-Wiedemann syndrome with cancer and birth defects," The American Journal of Human Genetics, vol. 70, no. 3, pp. 604-611, 2002.

[90] C. Faulk and D. C. Dolinoy, "Timing is everything: the when and how of environmentally induced changes in the epigenome of animals," Epigenetics, vol. 6, no. 7, pp. 791-797, 2011.

[91] D. J. P. Barker, "The developmental origins of chronic adult disease," Acta Paediatrica, Supplement, vol. 93, no. 446, pp. 2633, 2004.

[92] M. Hanson, K. M. Godfrey, K. A. Lillycrop, G. C. Burdge, and P. D. Gluckman, "Developmental plasticity and developmental origins of non-communicable disease: theoretical considerations and epigenetic mechanisms," Progress in Biophysics and Molecular Biology, vol. 106, no. 1, pp. 272-280, 2011.

[93] P. D. Wadhwa, C. Buss, S. Entringer, and J. M. Swanson, "Developmental origins of health and disease: brief history of the approach and current focus on epigenetic mechanisms," Seminars in Reproductive Medicine, vol. 27, no. 5, pp. 358-368, 2009.

[94] E. Jablonka, "Epigenetic epidemiology," International Journal of Epidemiology, vol. 33, no. 5, pp. 929-935, 2004.

[95] V. Calvanese, E. Lara, A. Kahn, and M. F. Fraga, "The role of epigenetics in aging and age-related diseases," Ageing Research Reviews, vol. 8, no. 4, pp. 268-276, 2009.

[96] M. F. Fraga, "Genetic and epigenetic regulation of aging," Current Opinion in Immunology, vol. 21, no. 4, pp. 446-453, 2009.

[97] C. D’Addario, B. Dell'Osso, M. C. Palazzo et al., "Selective DNA methylation of BDNF promoter in bipolar disorder: differences among patients with BDI and BDII," Neuropsychopharmacology, vol. 37, no. 7, pp. 1647-1655, 2012.

[98] F. Sananbenesi and A. Fischer, "The epigenetic bottleneck of neurodegenerative and psychiatric diseases," Biological Chemistry, vol. 390, no. 11, pp. 1145-1153, 2009.

[99] R. G. Urdinguio, J. V. Sanchez-Mut, and M. Esteller, "Epigenetic mechanisms in neurological diseases: genes, syndromes, and therapies," The Lancet Neurology, vol. 8, no. 11, pp. 1056-1072, 2009.

[100] L. Chouliaras, B. P. F. Rutten, G. Kenis et al., "Epigenetic regulation in the pathophysiology of Alzheimer's disease," Progress in Neurobiology, vol. 90, no. 4, pp. 498-510, 2010.

[101] D. Mastroeni, A. Grover, E. Delvaux, C. Whiteside, P. D. Coleman, and J. Rogers, "Epigenetic mechanisms in Alzheimer's disease," Neurobiology of Aging, vol. 32, no. 7, pp. 1161-1180, 2011.

[102] J. Mill, "Toward an integrated genetic and epigenetic approach to Alzheimer's disease," Neurobiology of Aging, vol. 32, no. 7, pp. 1188-1191, 2011.

[103] M. Barrachina and I. Ferrer, "DNA methylation of Alzheimer disease and tauopathy-related genes in postmortem brain," Journal of Neuropathology and Experimental Neurology, vol. 68, no. 8, pp. 880-891, 2009.

[104] H. Tohgi, K. Utsugisawa, Y. Nagane, M. Yoshimura, Y. Genda, and M. Ukitsu, "Reduction with age in methylcytosine in the promoter region -224 -101 of the amyloid precursor protein gene in autopsy human cortex," Molecular Brain Research, vol. 70, no. 2, pp. 288-292, 1999.

[105] H. Tohgi, K. Utsugisawa, Y. Nagane, M. Yoshimura, M. Ukitsu, and Y. Genda, "The methylation status of cytosines in a $\tau$ gene promoter region alters with age to downregulate transcriptional 
activity in human cerebral cortex," Neuroscience Letters, vol. 275, no. 2, pp. 89-92, 1999.

[106] D. Mastroeni, A. Grover, E. Delvaux, C. Whiteside, P. D. Coleman, and J. Rogers, "Epigenetic changes in Alzheimer's disease: decrements in DNA methylation," Neurobiology of Aging, vol. 31, no. 12, pp. 2025-2037, 2010.

[107] D. Mastroeni, A. McKee, A. Grover, J. Rogers, and P. D. Coleman, "Epigenetic differences in cortical neurons from a pair of monozygotic twins discordant for Alzheimer's disease," PLoS ONE, vol. 4, no. 8, Article ID e6617, 2009.

[108] J. Nunez-Iglesias, C.-C. Liu, T. E. Morgan, C. E. Finch, and X. J. Zhou, "Joint genome-wide profiling of miRNA and mRNA expression in Alzheimer's disease cortex reveals altered miRNA regulation," PloS ONE, vol. 5, no. 2, Article ID e8898, 2010.

[109] O. Ogawa, X. Zhu, H.-G. Lee et al., "Ectopic localization of phosphorylated histone $\mathrm{H} 3$ in Alzheimer's disease: a mitotic catastrophe?" Acta Neuropathologica, vol. 105, no. 5, pp. 524$528,2003$.

[110] A. Fuso, L. Seminara, R. A. Cavallaro, F. D’Anselmi, and S. Scarpa, "S-adenosylmethionine/homocysteine cycle alterations modify DNA methylation status with consequent deregulation of PS1 and BACE and beta-amyloid production," Molecular and Cellular Neuroscience, vol. 28, no. 1, pp. 195-204, 2005.

[111] M. Belakavadi, J. Dell, G. J. Grover, and J. D. Fondell, “Thyroid hormone suppression of $\beta$-amyloid precursor protein gene expression in the brain involves multiple epigenetic regulatory events," Molecular and Cellular Endocrinology, vol. 339, no. 1-2, pp. 72-80, 2011.

[112] F. Dangond and S. R. Gullans, "Differential expression of human histone deacetylase mRNAs in response to immune cell apoptosis induction by Trichostatin A and butyrate," Biochemical and Biophysical Research Communications, vol. 247, no. 3, pp. 833837, 1998.

[113] A. J. M. de Ruijter, A. H. van Gennip, H. N. Caron, S. Kemp, and A. B. P. van Kuilenburg, "Histone deacetylases (HDACs): characterization of the classical HDAC family," Biochemical Journal, vol. 370, part 3, pp. 737-749, 2003.

[114] A. di Francesco, B. Arosio, C. Gussago et al., "Involvement of 5-lipoxygenase in Alzheimer's disease: a role for DNA methylation," Journal of Alzheimer's Disease, vol. 37, no. 1, pp. 3-8, 2013.

[115] C. D’Addario, A. Di Francesco, B. Arosio et al., "Epigenetic regulation of fatty acid amide hydrolase in Alzheimer disease," PLoS ONE, vol. 7, no. 6, Article ID e39186, 2012.

[116] M. van der Stelt, J. A. van Kuik, M. Bari et al., "Oxygenated metabolites of anandamide and 2-arachidonoylglycerol: conformational analysis and interaction with cannabinoid receptors, membrane transporter, and fatty acid amide hydrolase," Journal of Medicinal Chemistry, vol. 45, no. 17, pp. 3709-3720, 2002.

[117] C. A. Rouzer and L. J. Marnett, "Endocannabinoid oxygenation by cyclooxygenases, lipoxygenases, and cytochromes P450: cross-talk between the eicosanoid and endocannabinoid signaling pathways," Chemical Reviews, vol. 111, no. 10, pp. 5899-5921, 2011.

[118] C. Benito, E. Núñez, R. M. Tolón et al., "Cannabinoid $\mathrm{CB}_{2}$ receptors and fatty acid amide hydrolase are selectively overexpressed in neuritic plaque-associated glia in Alzheimer's disease brains," Journal of Neuroscience, vol. 23, no. 35, pp. 11136-11141, 2003.

[119] C. Cunningham and D. T. Skelly, "Non-steroidal antiinflammatory drugs and cognitive function: are prostaglandins at the heart of cognitive impairment in dementia and delirium?" Journal of NeuroImmune Pharmacology, vol. 7, no. 1, pp. 60-73, 2012.

[120] B. P. Imbimbo, V. Solfrizzi, and F. Panza, "Are NSAIDs useful to treat Alzheimer's disease or mild cognitive impairment?" Frontiers in Aging Neuroscience, 2010.

[121] S. C. Ng and F. K. Chan, "NSAID-induced gastrointestinal and cardiovascular injury," Current Opinion in Gastroenterology, vol. 26, no. 6, pp. 611-617, 2010.

[122] G. J. Petot and R. P. Friedland, "Lipids, diet and Alzheimer disease: an extended summary," Journal of the Neurological Sciences, vol. 226, no. 1-2, pp. 31-33, 2004.

[123] A. Mendonça and R. A. Cunha, “Therapeutic opportunities for caffeine in Alzheimer's disease and other neurodegenerative disorders," Journal of Alzheimer's Disease, vol. 20, supplement 1, pp. S1-S2, 2010.

[124] G. W. Arendash, W. Schleif, K. Rezai-Zadeh et al., "Caffeine protects Alzheimer's mice against cognitive impairment and reduces brain $\beta$-amyloid production," Neuroscience, vol. 142, no. 4, pp. 941-952, 2006.

[125] A. J. Carter, W. T. O’Connor, M. J. Carter, and U. Ungerstedt, "Caffeine enhances acetylcholine release in the hippocampus in vivo by a selective interaction with adenosine $\mathrm{A}_{1}$ receptors," Journal of Pharmacology and Experimental Therapeutics, vol. 273, no. 2, pp. 637-642, 1995.

[126] O. P. Dall'Igna, P. Fett, M. W. Gomes, D. O. Souza, R. A. Cunha, and D. R. Lara, "Caffeine and adenosine $\mathrm{A}_{2 \mathrm{~A}}$ receptor antagonists prevent $\beta$-amyloid (25-35)-induced cognitive deficits in mice," Experimental Neurology, vol. 203, no. 1, pp. 241-245, 2007.

[127] M. Johnson-Kozlow, D. Kritz-Silverstein, E. Barrett-Connor, and D. Morton, "Coffee consumption and cognitive function among older adults," The American Journal of Epidemiology, vol. 156, no. 9, pp. 842-850, 2002.

[128] M. P. J. van Boxtel, J. A. J. Schmitt, H. Bosma, and J. Jolles, "The effects of habitual caffeine use on cognitive change: a longitudinal perspective," Pharmacology Biochemistry and Behavior, vol. 75, no. 4, pp. 921-927, 2003.

[129] B. B. Fredholm, K. Bättig, J. Holmén, A. Nehlig, and E. E. Zvartau, "Actions of caffeine in the brain with special reference to factors that contribute to its widespread use," Pharmacological Reviews, vol. 51, no. 1, pp. 83-133, 1999.

[130] G. Haskó, J. Linden, B. Cronstein, and P. Pacher, "Adenosine receptors: therapeutic aspects for inflammatory and immune diseases," Nature Reviews Drug Discovery, vol. 7, no. 9, pp. 759770, 2008.

[131] J. P. Headrick, K. J. Ashton, R. B. Rose'meyer, and J. N. Peart, "Cardiovascular adenosine receptors: expression, actions and interactions," Pharmacology \& Therapeutics, vol. 140, no. 1, pp. 92-111, 2013.

[132] B. B. Fredholm, Y. Chern, R. Franco, and M. Sitkovsky, "Aspects of the general biology of adenosine $\mathrm{A}_{2 \mathrm{~A}}$ signaling," Progress in Neurobiology, vol. 83, no. 5, pp. 263-276, 2007.

[133] J. Linden, "Molecular approach to adenosine receptors: receptor-mediated mechanisms of tissue protection," Annual Review of Pharmacology and Toxicology, vol. 41, pp. 775-787, 2001.

[134] A. M. Sebastião and J. A. Ribeiro, "Tuning and fine-tuning of synapses with adenosine," Current Neuropharmacology, vol. 7, no. 3, pp. 180-194, 2009.

[135] B. N. Cronstein, S. B. Kramer, E. D. Rosenstein, G. Weissmann, and R. Hirschhorn, "Adenosine modulates the generation of 
superoxide anion by stimulated human neutrophils via interaction with a specific cell surface receptor," Annals of the New York Academy of Sciences, vol. 451, pp. 291-301, 1985.

[136] M. Koshiba, H. Kojima, S. Huang, S. Apasov, and M. V. Sitkovsky, "Memory of extracellular adenosine $\mathrm{A}_{2 \mathrm{~A}}$ purinergic receptor-mediated signaling in murine $\mathrm{T}$ cells," Journal of Biological Chemistry, vol. 272, no. 41, pp. 25881-25889, 1997.

[137] M. Sitkovsky and D. Lukashev, "Regulation of immune cells by local-tissue oxygen tension: HIFl $\alpha$ and adenosine receptors," Nature Reviews Immunology, vol. 5, no. 9, pp. 712-721, 2005.

[138] J.-F. Chen, P. K. Sonsalla, F. Pedata et al., "Adenosine $A_{2 A}$ receptors and brain injury: broad spectrum of neuroprotection, multifaceted actions and "fine tuning" modulation," Progress in Neurobiology, vol. 83, no. 5, pp. 310-331, 2007.

[139] R. J. Rodrigues, P. M. Canas, L. V. Lopes, C. R. Oliveira, and R. A. Cunha, "Modification of adenosine modulation of acetylcholine release in the hippocampus of aged rats," Neurobiology of Aging, vol. 29, no. 10, pp. 1597-1601, 2008.

[140] M. V. Sitkovsky, "Use of the $\mathrm{A}_{2 \mathrm{~A}}$ adenosine receptor as a physiological immunosuppressor and to engineer inflammation in vivo," Biochemical Pharmacology, vol. 65, no. 4, pp. 493-501, 2003.

[141] M. V. Sitkovsky, D. Lukashev, S. Apasov et al., "Physiological control of immune response and inflammatory tissue damage by hypoxia-inducible factors and adenosine $\mathrm{A}_{2 \mathrm{~A}}$ receptors," Annual Review of Immunology, vol. 22, pp. 657-682, 2004.

[142] A. M. Sebastião and J. A. Ribeiro, "Adenosine receptors and the central nervous system," Handbook of Experimental Pharmacology, vol. 193, pp. 471-534, 2009.

[143] T. W. Stone, S. Ceruti, and M. P. Abbracchio, "Adenosine receptors and neurological disease: neuroprotection and neurodegeneration," Handbook of Experimental Pharmacology, vol. 193, pp. 535-587, 2009.

[144] P. M. Canas, L. O. Porciúncula, G. M. A. Cunha et al., "Adenosine $\mathrm{A}_{2 \mathrm{~A}}$ receptor blockade prevents synaptotoxicity and memory dysfunction caused by $\beta$-amyloid peptides via p38 mitogen-activated protein kinase pathway," Journal of Neuroscience, vol. 29, no. 47, pp. 14741-14751, 2009.

[145] R. A. Cunha, "Neuroprotection by adenosine in the brain: from $\mathrm{A}_{1}$ receptor activation to $\mathrm{A}_{2 \mathrm{~A}}$ receptor blockade," Purinergic Signalling, vol. 1, no. 2, pp. 111-134, 2005.

[146] N. Rebola, R. Lujan, R. A. Cunha, and C. Mulle, "Adenosine $A_{2 A}$ receptors are essential for long-term potentiation of NMDAEPSCs at hippocampal mossy fiber synapses," Neuron, vol. 57, no. 1, pp. 121-134, 2008.

[147] B. B. Fredholm, J.-F. Chen, R. A. Cunha, P. Svenningsson, and J.-M. Vaugeois, "Adenosine and brain function," International Review of Neurobiology, vol. 63, pp. 191-270, 2005.

[148] C. V. Gomes, M. P. Kaster, A. R. Tomé, P. M. Agostinho, and R. A. Cunha, "Adenosine receptors and brain diseases: neuroprotection and neurodegeneration," Biochimica et Biophysica Acta, vol. 1808, no. 5, pp. 1380-1399, 2011.

[149] J. W. Phillis, "The effects of selective $A_{1}$ and $A_{2 A}$ adenosine receptor antagonists on cerebral ischemic injury in the gerbil," Brain Research, vol. 705, no. 1-2, pp. 79-84, 1995.

[150] P. A. Jones, R. A. Smith, and T. W. Stone, "Protection against kainate-induced excitotoxicity by adenosine $\mathrm{A}_{2 \mathrm{~A}}$ receptor agonists and antagonists," Neuroscience, vol. 85, no. 1, pp. 229-237, 1998.

[151] M. A. H. Talukder, R. R. Morrison, C. Ledent, and S. J. Mustafa, "Endogenous adenosine increases coronary flow by activation of both $\mathrm{A}_{2 \mathrm{~A}}$ and $\mathrm{A}_{2 \mathrm{~B}}$ receptors in mice," Journal of Cardiovascular Pharmacology, vol. 41, no. 4, pp. 562-570, 2003.

[152] A. Delikouras, L. D. Fairbanks, A. H. Simmonds, R. I. Lechler, and A. Dorling, "Endothelial cell cytoprotection induced in vitro by allo- or xenoreactive antibodies is mediated by signaling through adenosine $A_{2}$ receptors," European Journal of Immunology, vol. 33, no. 11, pp. 3127-3135, 2003.

[153] Y. Zhu, L. Liu, X. Peng, X. Ding, G. Yang, and T. Li, "Role of adenosine $A_{2 A}$ receptor in organ-specific vascular reactivity following hemorrhagic shock in rats," Journal of Surgical Research, vol. 184, no. 2, pp. 951-958, 2013.

[154] B. Arosio, C. Viazzoli, L. Mastronardi, C. Bilotta, C. Vergani, and L. Bergamaschini, "Adenosine A 2A receptor expression in peripheral blood mononuclear cells of patients with mild cognitive impairment," Journal of Alzheimer's Disease, vol. 20, no. 4, pp. 991-996, 2010.

[155] C. Gussago, B. Arosio, M. Casati et al., "Different adenosine $\mathrm{A}_{2 \mathrm{~A}}$ receptor expression in peripheral cells from elderly patients with vascular dementia and alzheimer's disease," Journal of Alzheimer's Disease, vol. 40, no. 1, pp. 45-49, 2014.

[156] S. Marques, V. L. Batalha, L. V. Lopes, and T. F. Outeiro, "Modulating alzheimer's disease through caffeine: a putative link to epigenetics," Journal of Alzheimer's Disease, vol. 24, supplement 2, pp. 161-171, 2011.

[157] A. A. Helmy, M. M. Abdel Naseer, S. El Shafie, and M. A. F. Nada, "Role of interleukin 6 and alpha-globulins in differentiating Alzheimer and vascular dementias," Neurodegenerative Diseases, vol. 9, no. 2, pp. 81-86, 2012.

[158] A. H. Simonsen, N. O. Hagnelius, G. Waldemar, T. K. Nilsson, and J. McGuire, "Protein markers for the differential diagnosis of vascular dementia and Alzheimer's disease ." International Journal of Proteomics, vol. 2012, Article ID 824024, 8 pages, 2012.

[159] J.-F. Chen, Z. Huang, J. Ma et al., " $A_{2 A}$ adenosine receptor deficiency attenuates brain injury induced by transient focal ischemia in mice," Journal of Neuroscience, vol. 19, no. 21, pp. 9192-9200, 1999.

[160] Z. J. Yang, B. Wang, H. Kwansa et al., "Adenosine $A_{2 A}$ receptor contributes to ischemic brain damage in newborn piglet," Journal of Cerebral Blood Flow \& Metabolism, vol. 33, no. 10, pp. 1612-1620, 2013.

[161] D. A. Pelligrino, H.-L. Xu, and F. Vetri, "Caffeine and the control of cerebral hemodynamics," Journal of Alzheimer's Disease, vol. 20, supplement 1, pp. S51-S62, 2010.

[162] S. Govoni, L. Gasparini, M. Racchi, and M. Trabucchi, "Peripheral cells as an investigational tool for Alzheimer's disease," Life Sciences, vol. 59, no. 5-6, pp. 461-468, 1996.

[163] D. Centonze, L. Battistini, and M. Maccarrone, "The endocannabinoid system in peripheral lymphocytes as a mirror of neuroinflammatory diseases," Current Pharmaceutical Design, vol. 14, no. 23, pp. 2370-2342, 2008. 


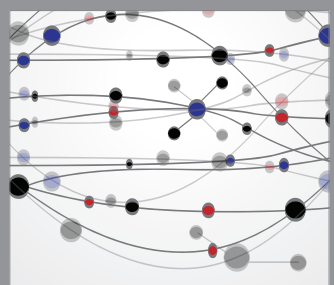

The Scientific World Journal
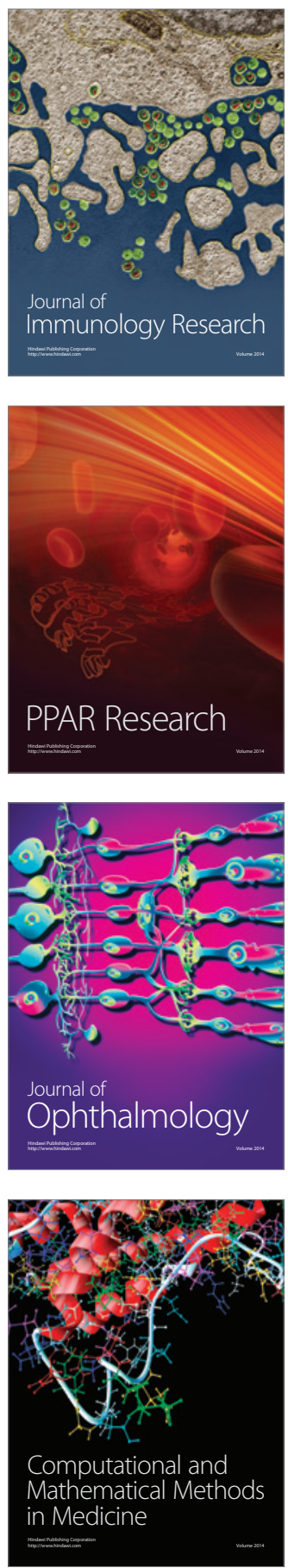

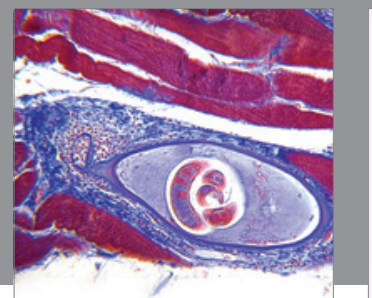

Gastroenterology

Research and Practice
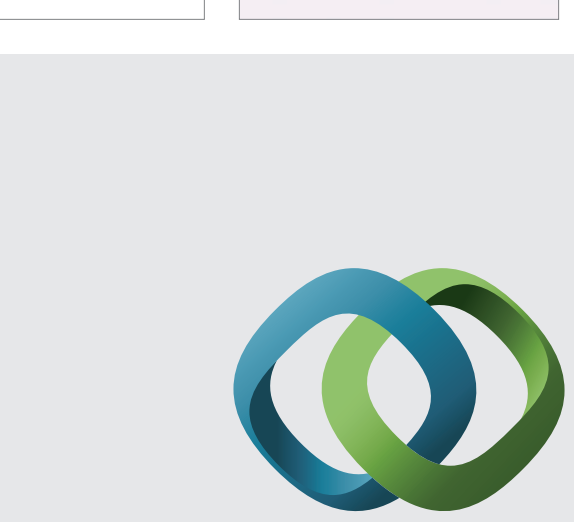

\section{Hindawi}

Submit your manuscripts at

http://www.hindawi.com
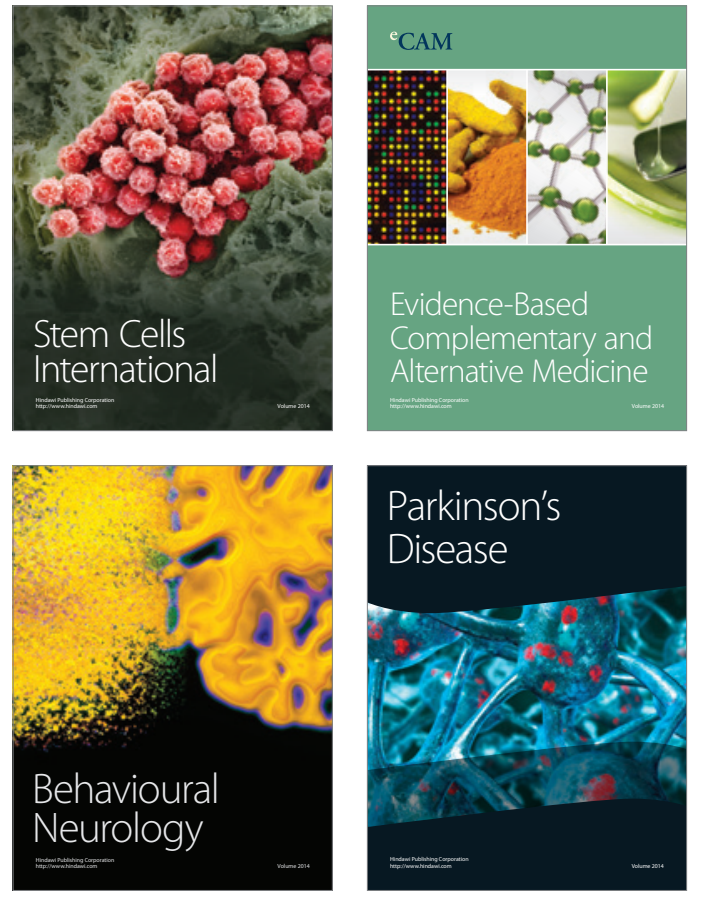
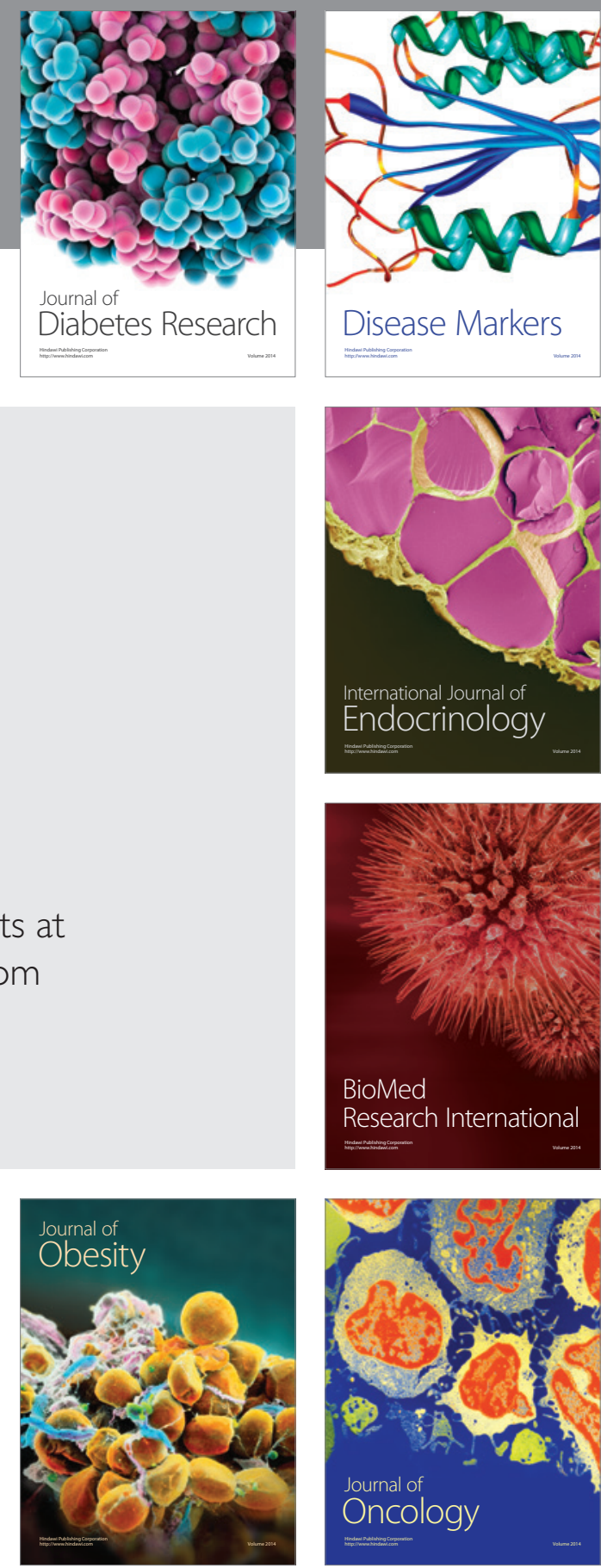

Disease Markers
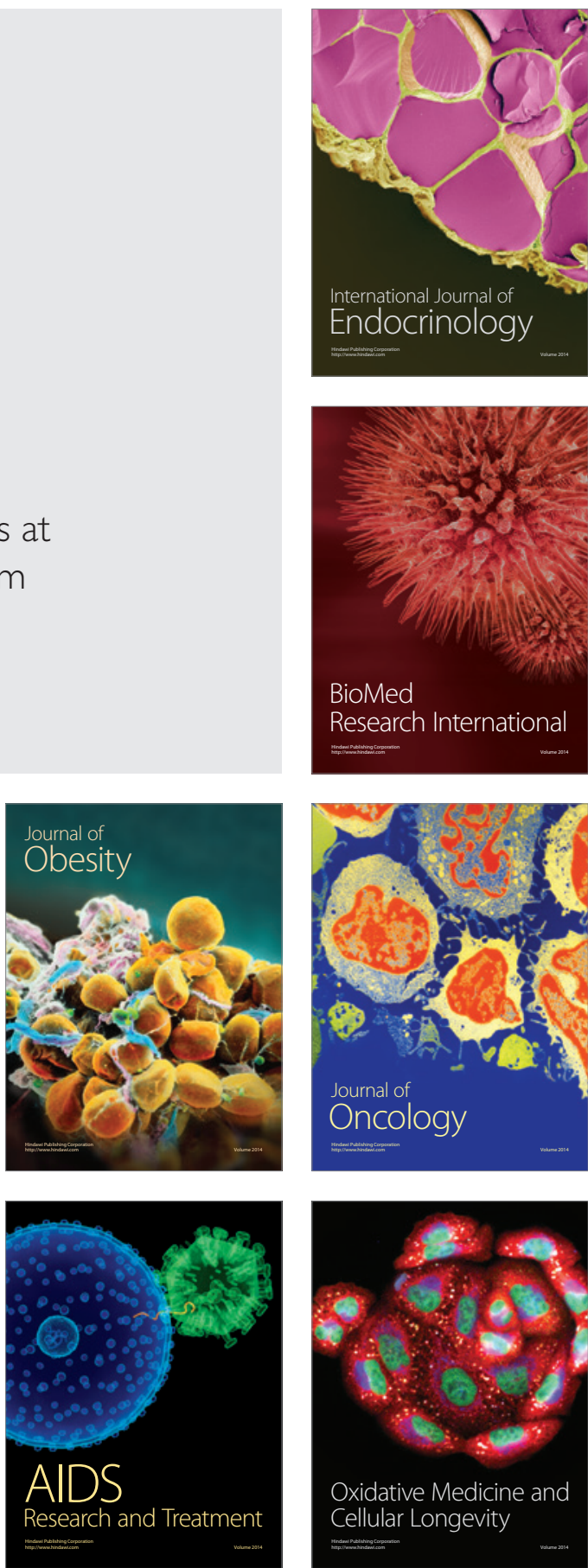